\title{
Development and Applications of ReaxFF Reactive Force Fields for Group-III Gas-Phase Precursors and Surface Reactions with Graphene in MOCVD Synthesis
}

Siavash Rajabpour ${ }^{1,2}$, Qian $\mathrm{Mao}^{3}$, Nadire Nayir ${ }^{3,4,5}$, Joshua A. Robinson ${ }^{2,4,6}$, Adri C.T. van Duin ${ }^{1,2,3,4,6 *}$

1. Department of Chemical Engineering, The Pennsylvania State University, University Park, PA 16802, USA

2. Center for Two-Dimensional and Layered Materials (2DLM), Material Research Institute, The Pennsylvania State University, University Park, PA 16802, USA

3. Department of Mechanical Engineering, The Pennsylvania State University, University Park, PA 16802, USA

4. Two-Dimensional Crystal Consortium (2DCC), Material Research Institute, The Pennsylvania State University, University Park, PA 16802, USA

5. Department of Physics, Karamanoglu Mehmetbey University, Karaman 70000, Turkey

6. Department of Materials Science and Engineering, The Pennsylvania State University, University Park, PA 16802, USA

*acv13@psu.edu 

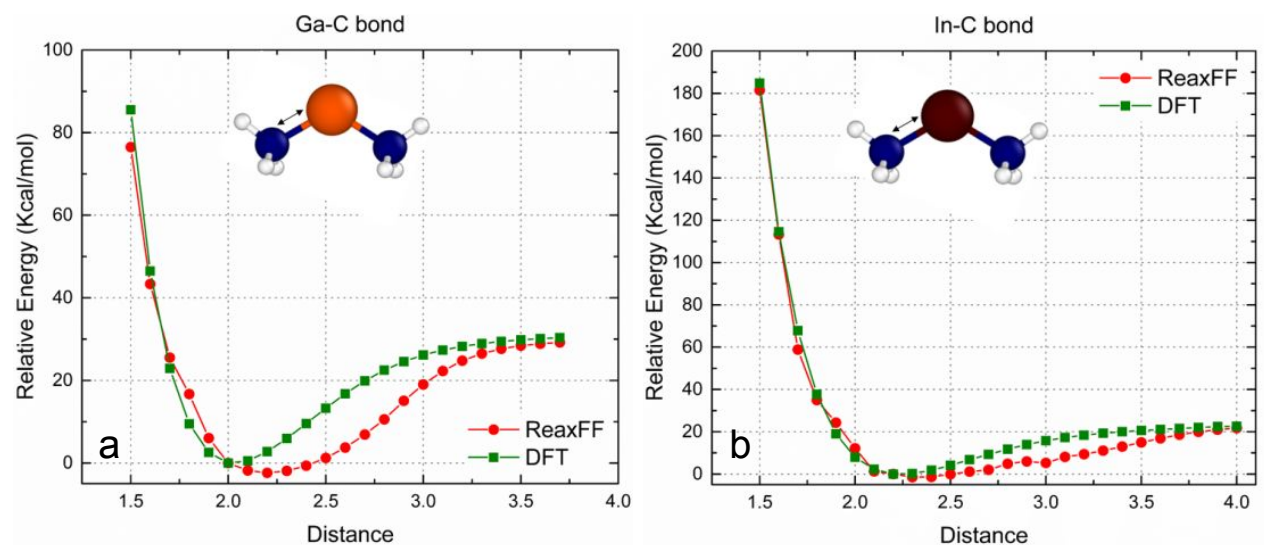

Figure S1. DFT (PVDZ++/B3LYP) and ReaxFF bond dissociation energies for (a) Ga-C bond in dimethylgallium $(\mathrm{DMGa})$ and (b) in In-C bond in dimethylindium (DMIn).
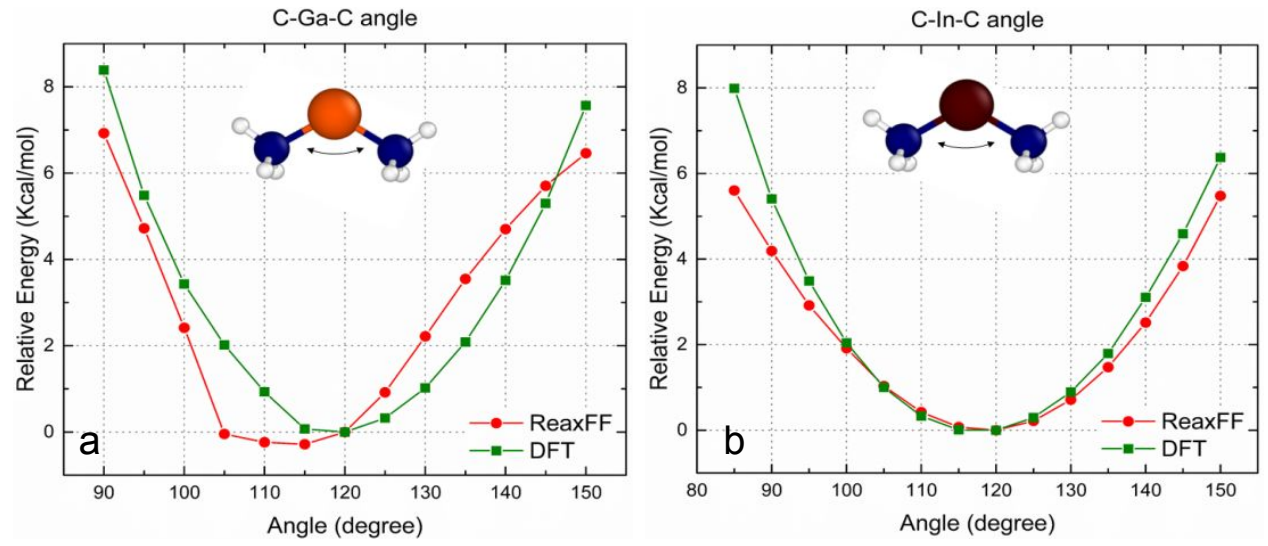

Figure S2. DFT (PVDZ++/B3LYP) and ReaxFF valence angle distortion energies for (a) $\mathrm{C}-\mathrm{Ga}-\mathrm{C}$ angle in dimethylgallium (DMGa) and (b) C-In-C angle in dimethylindium (DMIn).
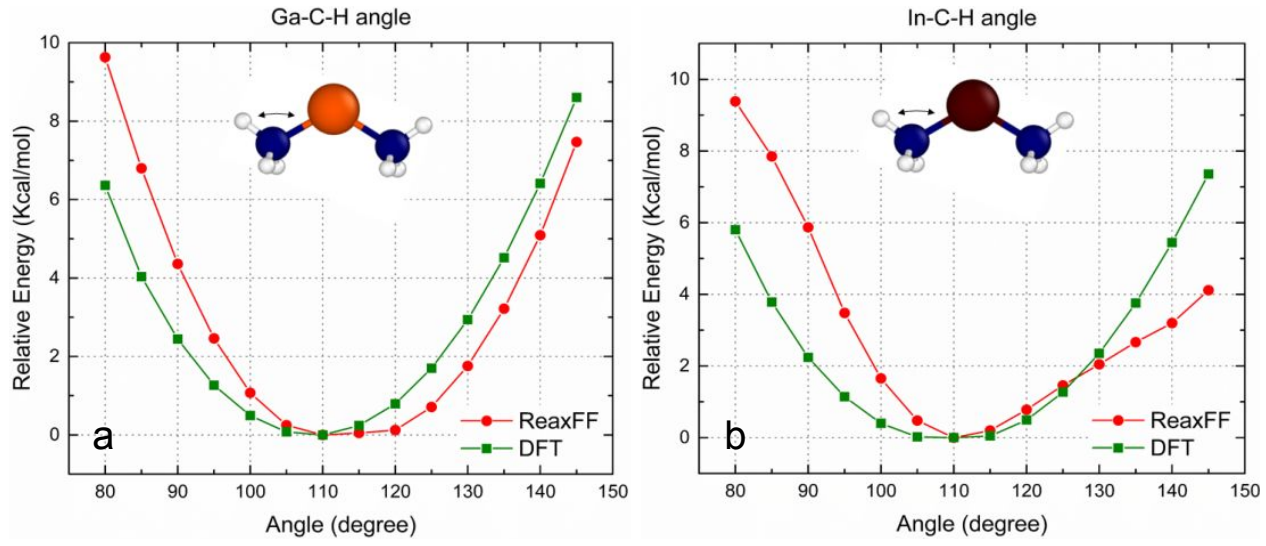

Figure S3. DFT (PVDZ++/B3LYP) and ReaxFF valence angle distortion energies for (a) Ga-C-H angle in dimethylgallium (DMGa) and (b) In-C-H angle in dimethylindium (DMIn). 

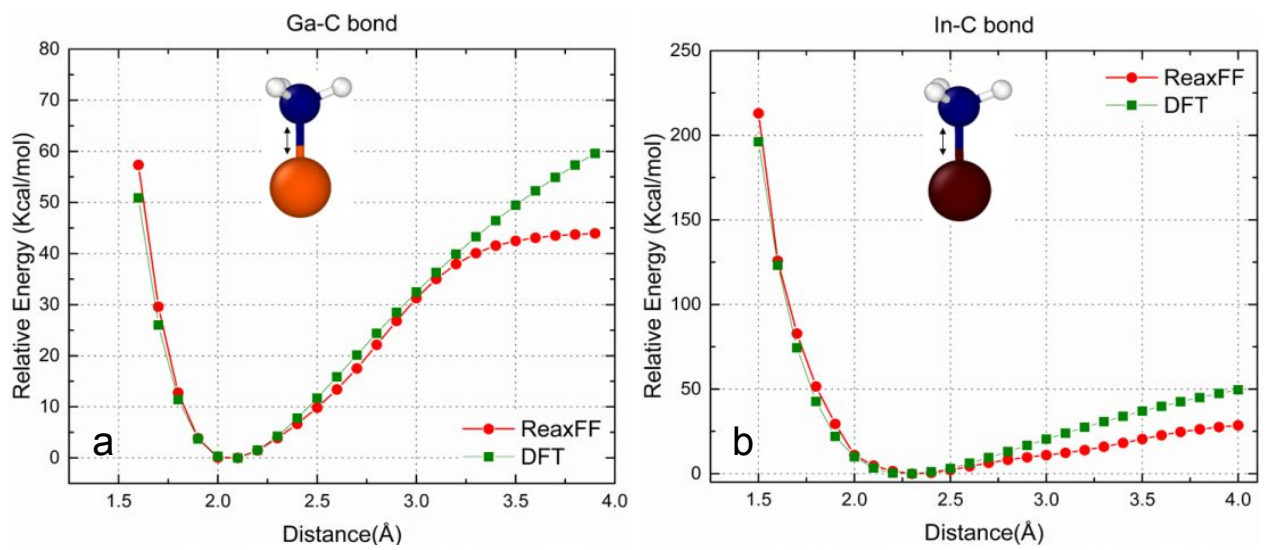

Figure S4. DFT (PVDZ++/B3LYP) and ReaxFF bond dissociation energies for (a) Ga-C bond in methylgallium (MGa) and (b) In-C bond in methylindium (MIn).
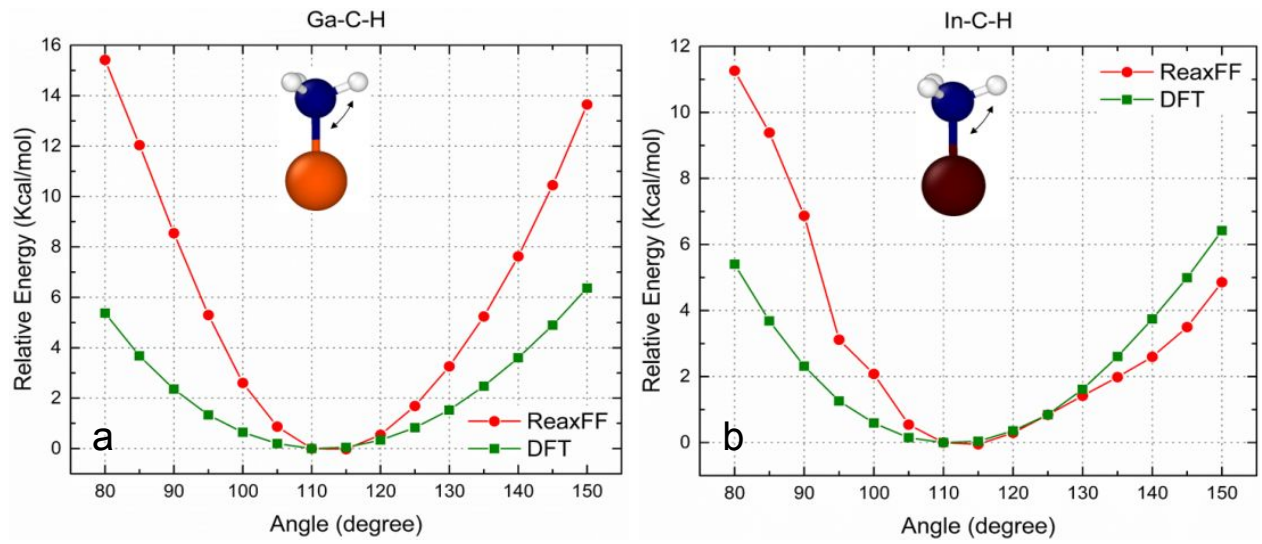

Figure S5. DFT (PVDZ++/B3LYP) and ReaxFF valence angle distortion energies for (a) Ga-C-H angle in methylgallium (MGa) and (b) In-C-H angle in methylindium (MIn).
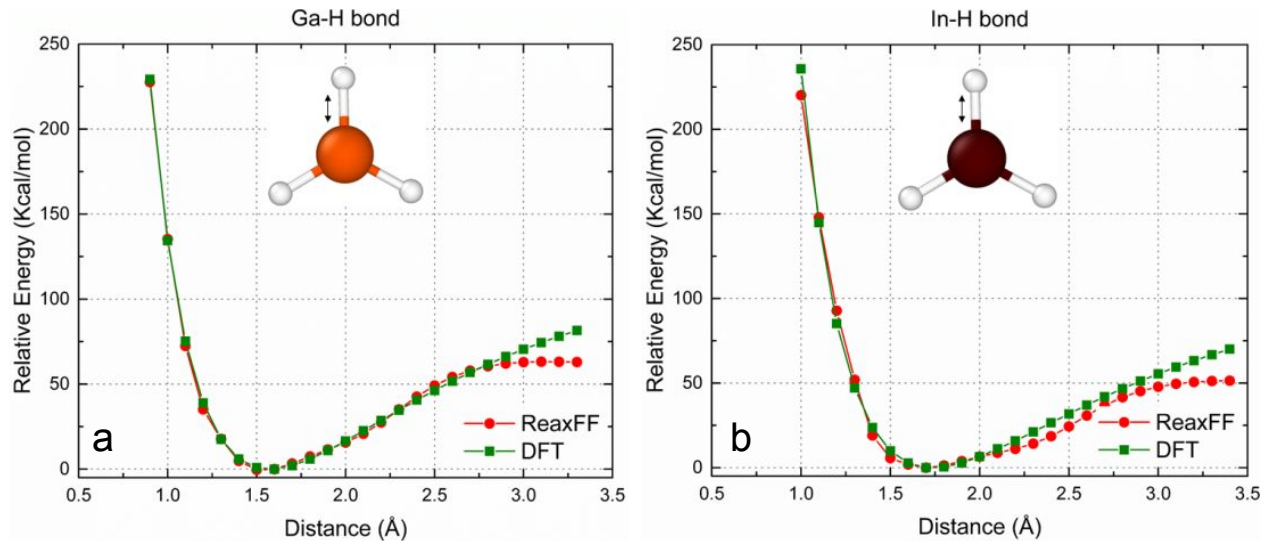

Figure S6. DFT (PVDZ++/B3LYP) and ReaxFF bond dissociation energies for (a) Ga-H bond in gallium hydride $\left(\mathrm{GaH}_{3}\right)$ and (b) In-H bond in indium hydride $\left(\mathrm{InH}_{3}\right)$. 

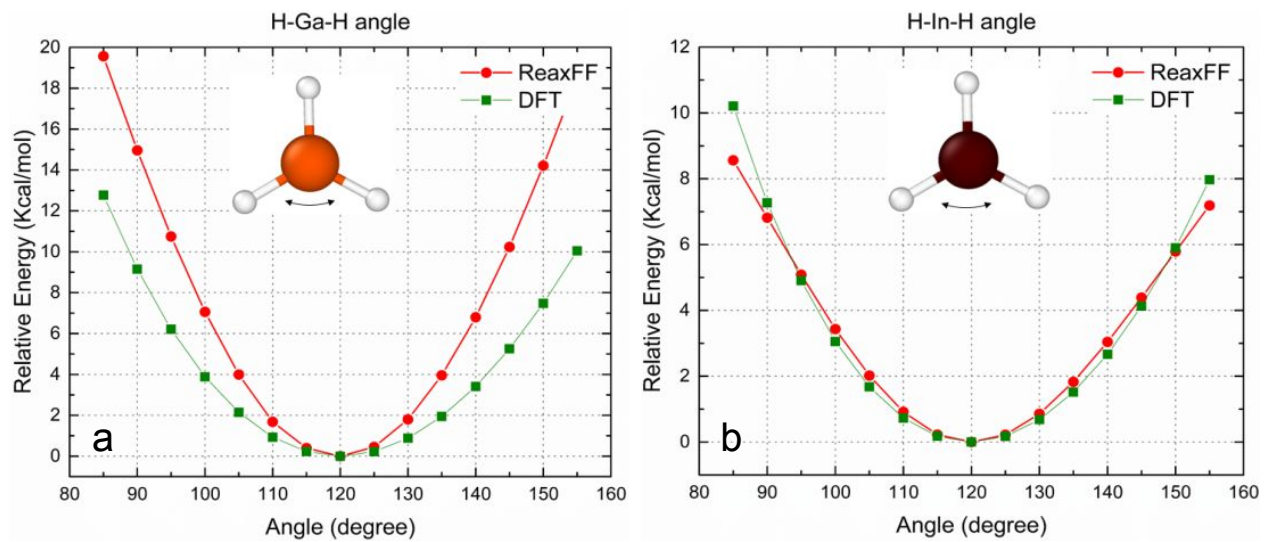

Figure S7. DFT (PVDZ++/B3LYP) and ReaxFF valence angle distortion energies for (a) H-Ga-H angle in gallium hydride $\left(\mathrm{GaH}_{3}\right)$ and (b) H-In-H angle in indium hydride $\left(\mathrm{InH}_{3}\right)$.
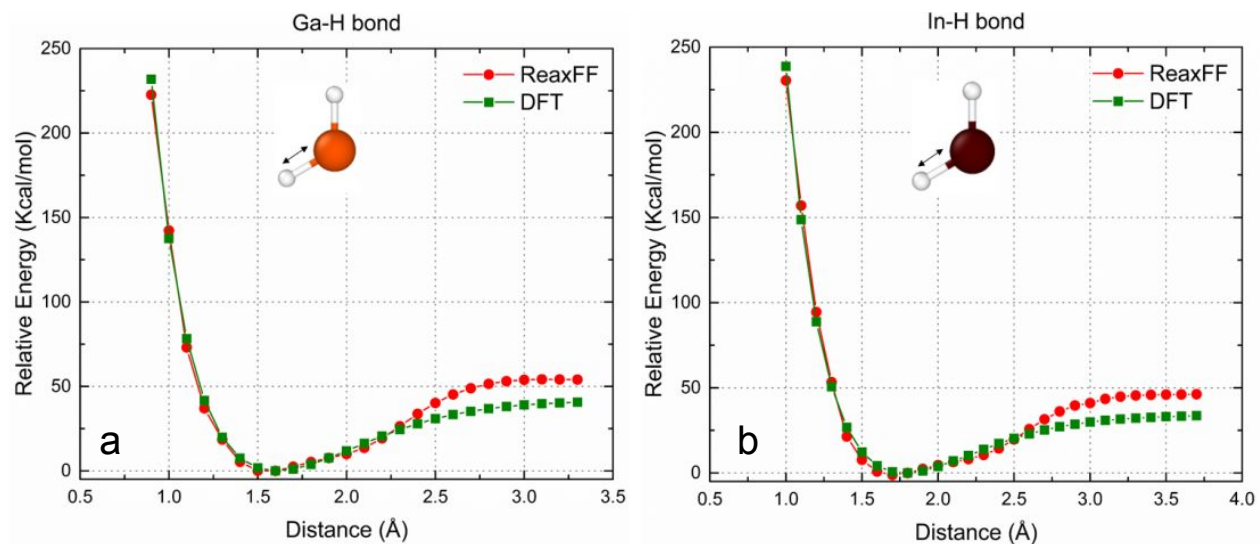

Figure S8. DFT (PVDZ++/B3LYP) and ReaxFF bond dissociation energies for (a) Ga-H bond in $\mathrm{GaH}_{2}$ and (b) In-H bond in $\mathrm{InH}_{2}$.
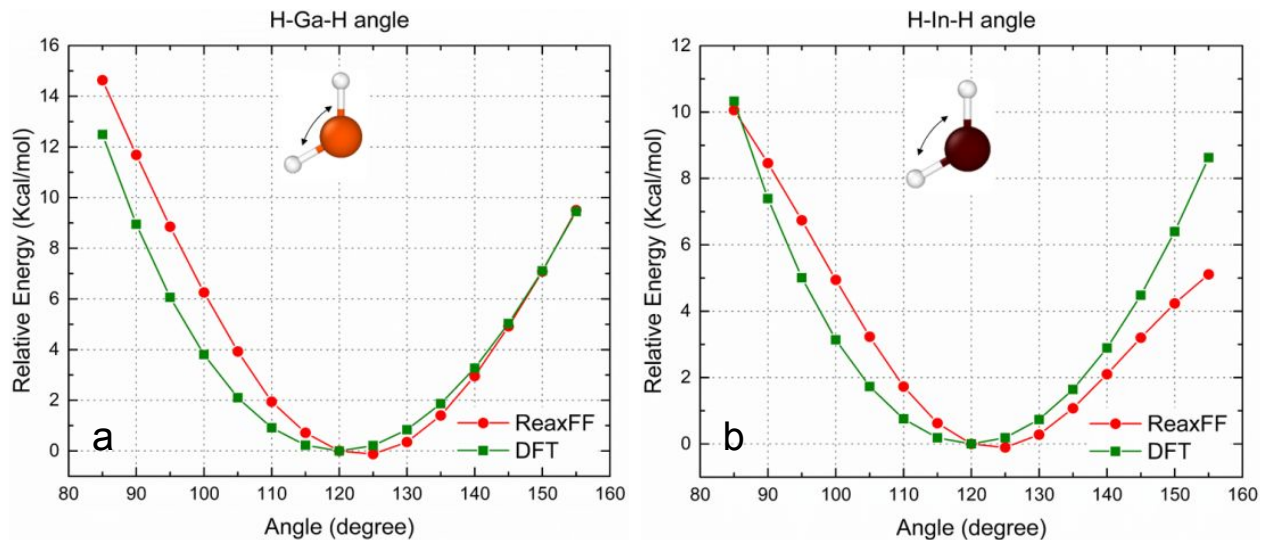

Figure S9. DFT (PVDZ++/B3LYP) and ReaxFF valence angle distortion energies for (a) $\mathrm{H}-\mathrm{Ga}-\mathrm{H}$ angle in $\mathrm{GaH}_{2}$ and (b) $\mathrm{H}-\mathrm{In}-\mathrm{H}$ angle in $\mathrm{InH}_{2}$. 

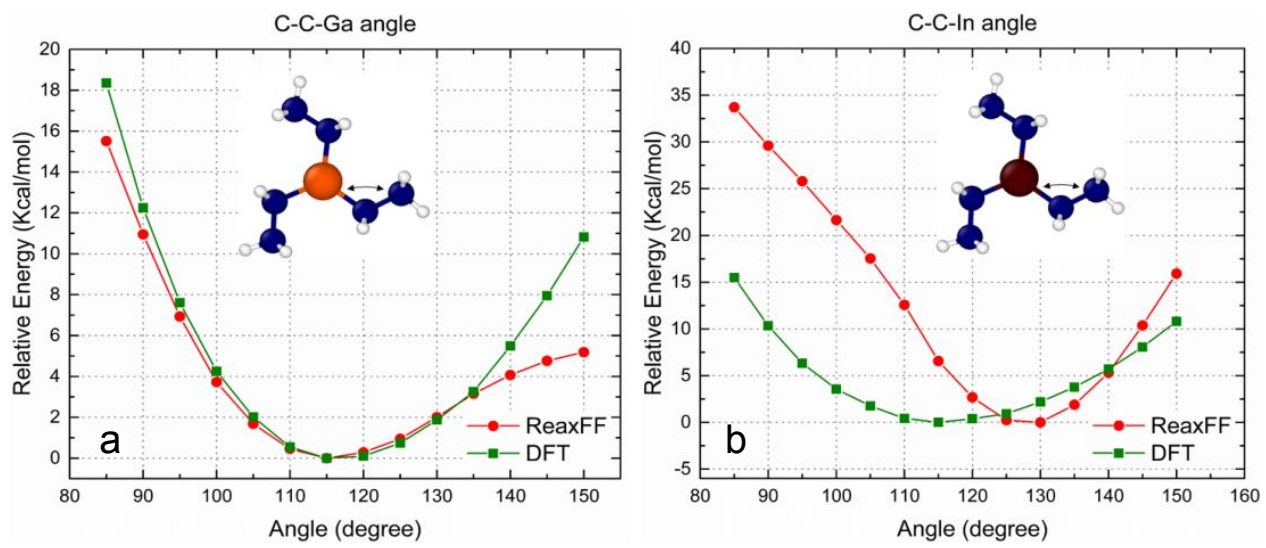

Figure S10. DFT (PVDZ++/B3LYP) and ReaxFF valence angle distortion energies for (a) $\mathrm{C}-\mathrm{C}-\mathrm{Ga}$ angle in triethylgallium (TEGa) and (b) C-C-In angle in triethylindium (TEIn).
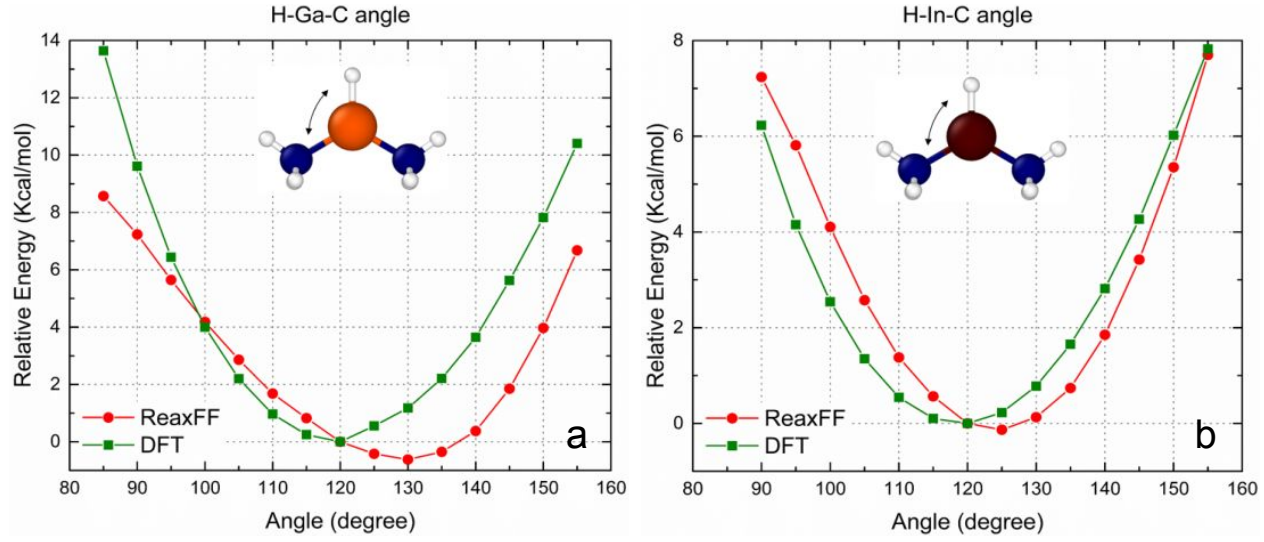

Figure S11. DFT (PVDZ++/B3LYP) and ReaxFF valence angle distortion energies for (a) $\mathrm{H}-\mathrm{Ga}-\mathrm{C}$ angle in $\mathrm{H}-\mathrm{DMGa}$ and (b) H-In-C angle in H-DMIn.
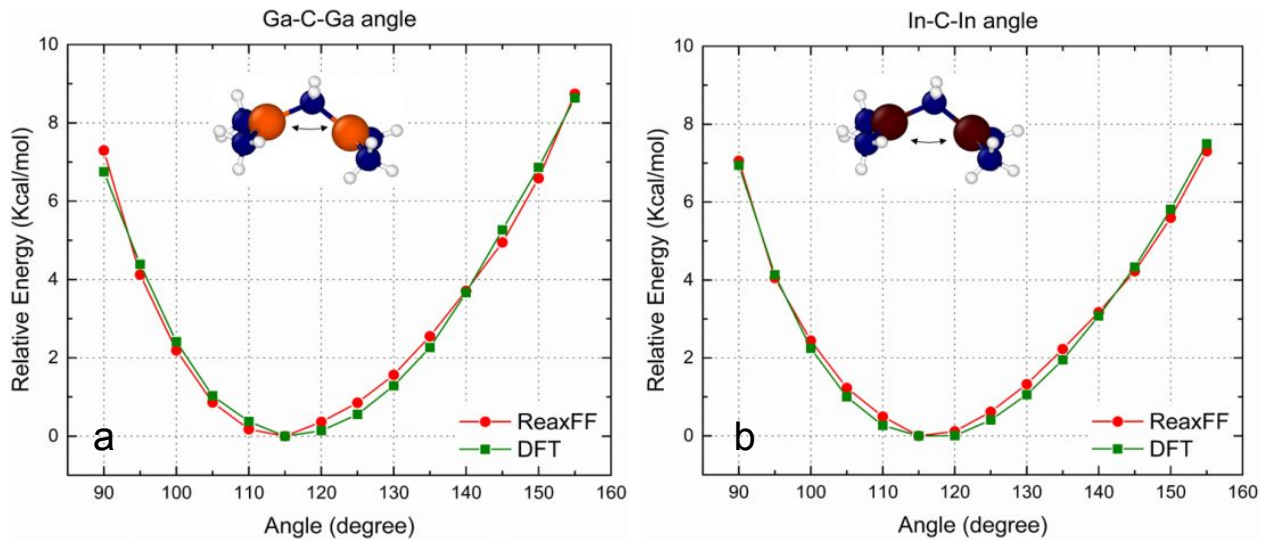

Figure S12. DFT (PVDZ++/B3LYP) and ReaxFF valence angle distortion energies for (a) Ga-C-Ga angle in DMGa$\mathrm{CH}_{2}$-DMGa and (b) In-C-In angle in DMIn- $\mathrm{CH}_{2}$-DMIn. 


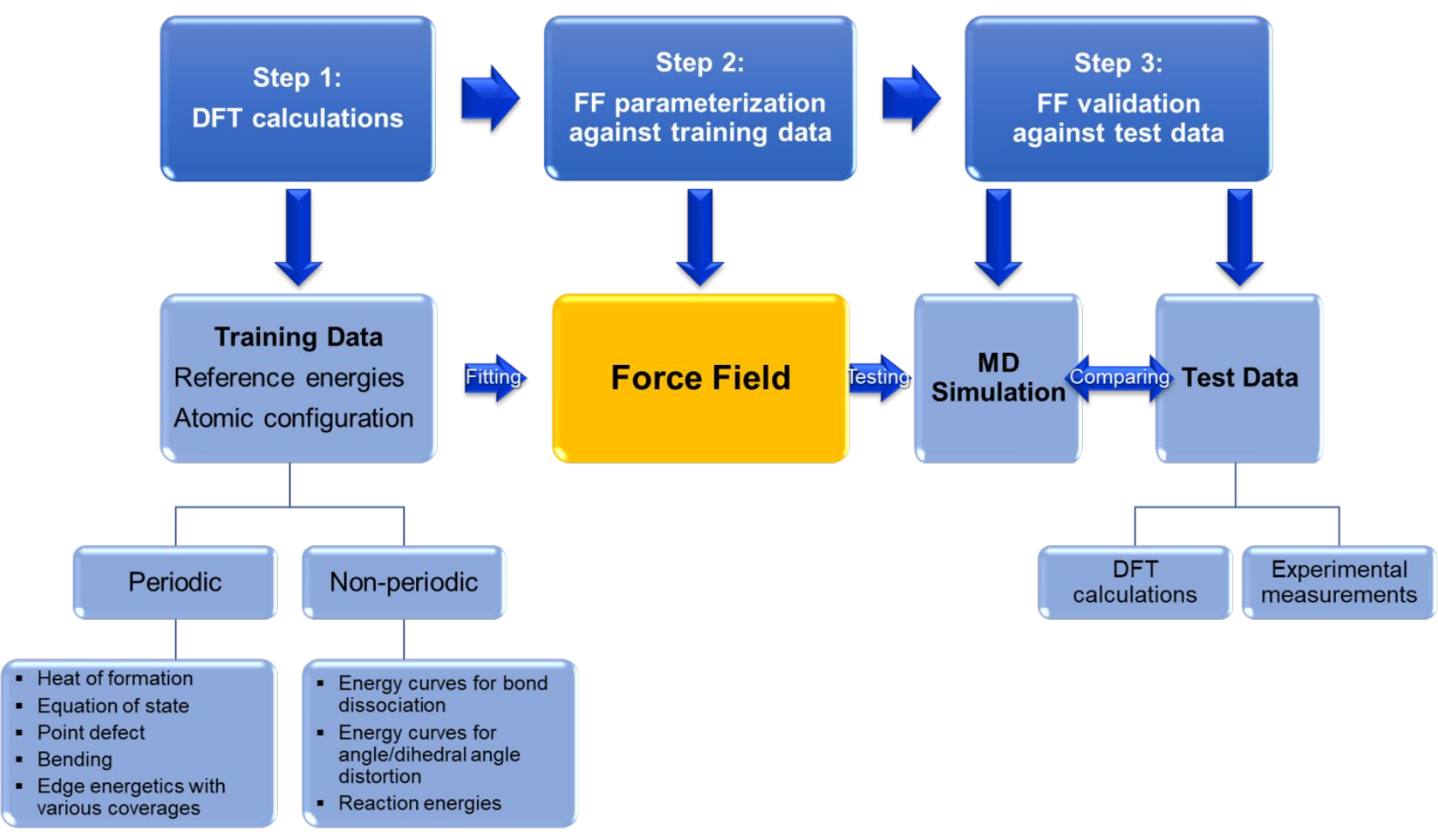

Figure S13. Flowchart illustrating the algorithm of ReaxFF force field parameterization and validation. 

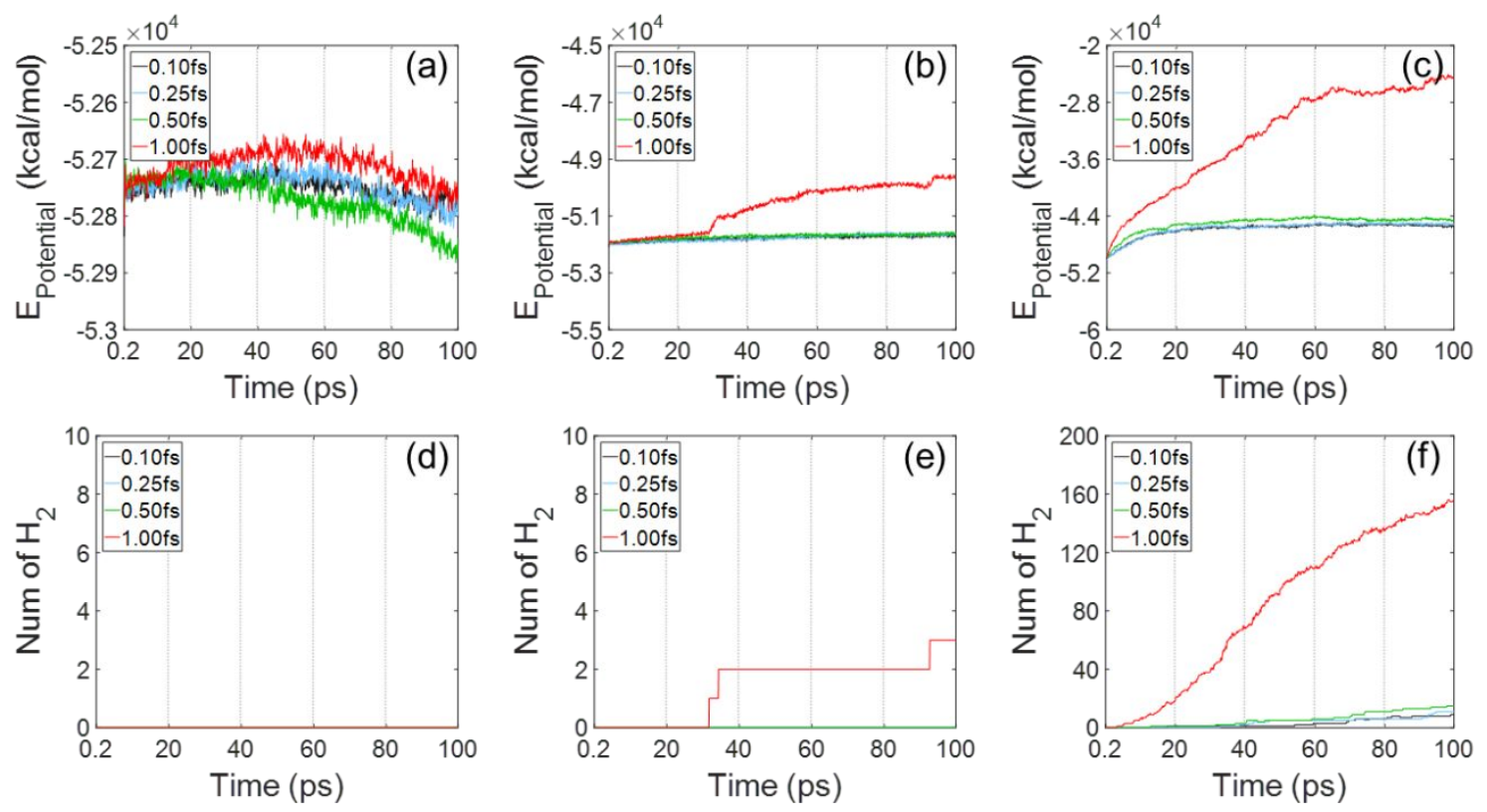

Figure S14. Comparisons of potential energies and hydrogen gas emissions among the use of different timesteps of $0.10 \mathrm{fs}, 0.25 \mathrm{fs}, 0.50 \mathrm{fs}$, and $1.00 \mathrm{fs}$ : Potential energy plots at (a) $300 \mathrm{~K}$, (b) $1000 \mathrm{~K}$, and (c) $2800 \mathrm{~K}$ from $0.2 \mathrm{ps}$ to $100 \mathrm{ps}$; Numbers of hydrogen gas molecules at (d) $300 \mathrm{~K}$, (e) $1000 \mathrm{~K}$, and (f) $2800 \mathrm{~K}$ from $0.2 \mathrm{ps}$ to $100 \mathrm{ps}$. 

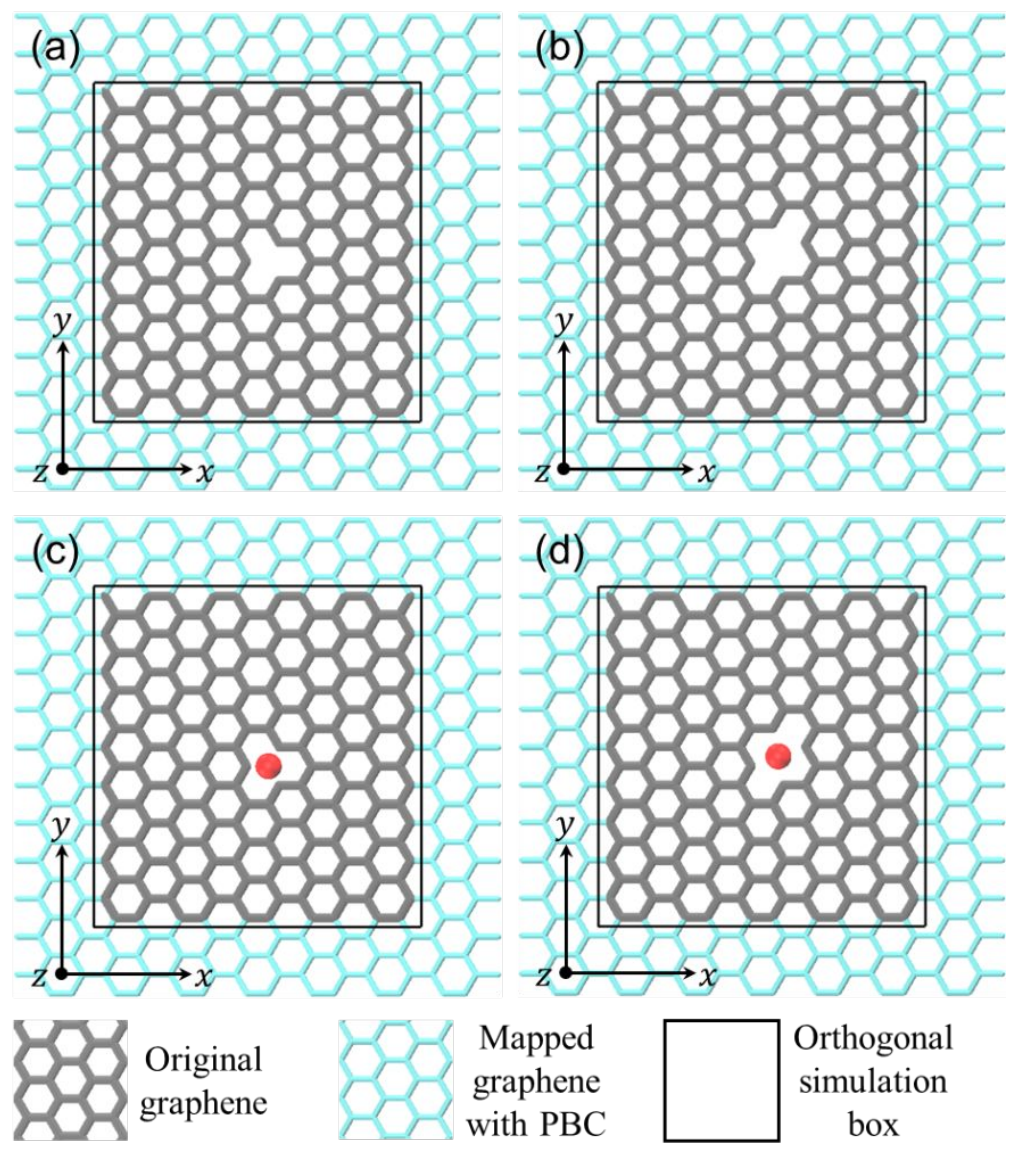

Orthogonal

simulation

Pre-doped $\mathrm{Ga} / \mathrm{In}$ atom

Figure S15. Initial configurations of monolayer graphene with (a) a bare monovacancy (MV), (b) a bare divacancy (DV); (c) an MV pre-doped by a Ga/In atom, and (d) a DV pre-doped by a $\mathrm{Ga} / \mathrm{In}$ atom. The periodic boundary condition (PBC) is applied to $x, y$, and $z$ directions for all cases. 

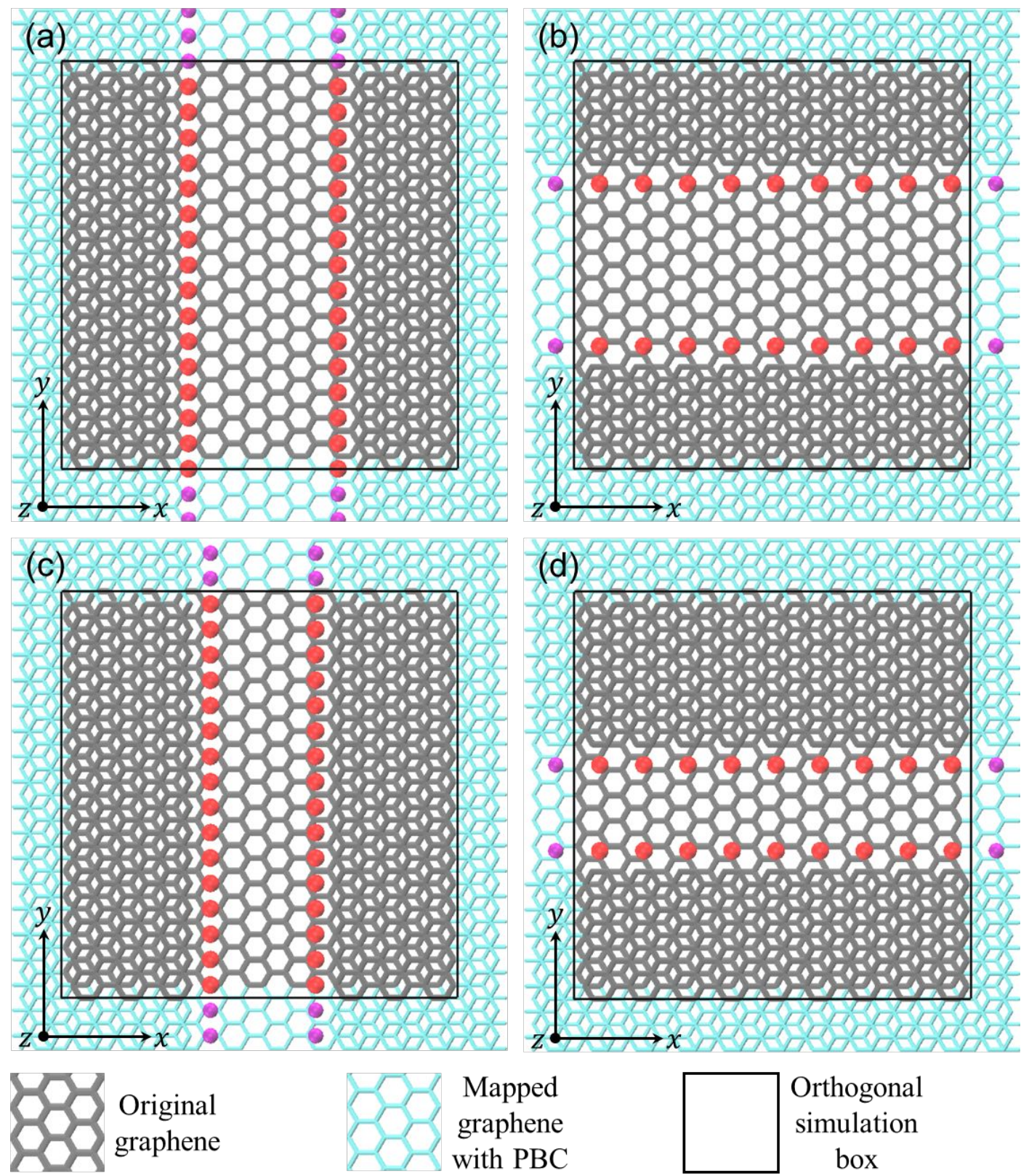

Pre-doped $\mathrm{Ga} / \mathrm{In}$ atom

Mapped pre-doped $\mathrm{Ga} / \mathrm{In}$ atom with PBC

Figure S16. Initial configurations of bi-layer (a) zigzag-edged graphene (ZZ-Gr) with an $18.46 \AA$ spacing, (b) armchair-edged graphene (AC-Gr) with a $19.68 \AA$ spacing, (c) ZZ-Gr with a $14.20 \AA$ spacing, and (d) AC-Gr with a $12.30 \AA$ spacing. The ZZ-Gr and AC-GR are functionalized by $32 \mathrm{Ga} / \mathrm{In}$ and $18 \mathrm{Ga} / \mathrm{In}$ atoms, respectively. The PBC is applied to $x, y$, and $z$ directions for all cases. 

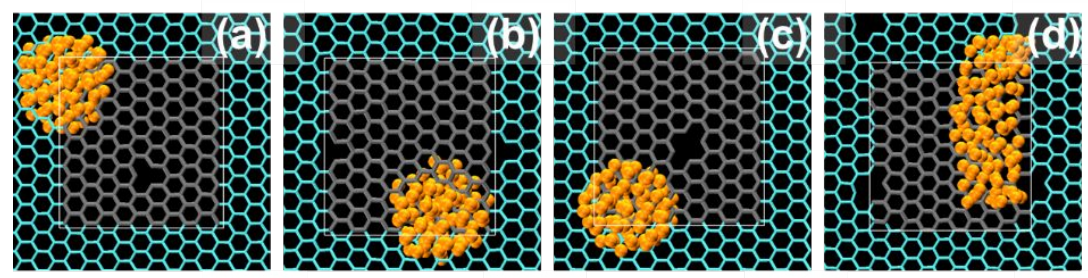

88 Original
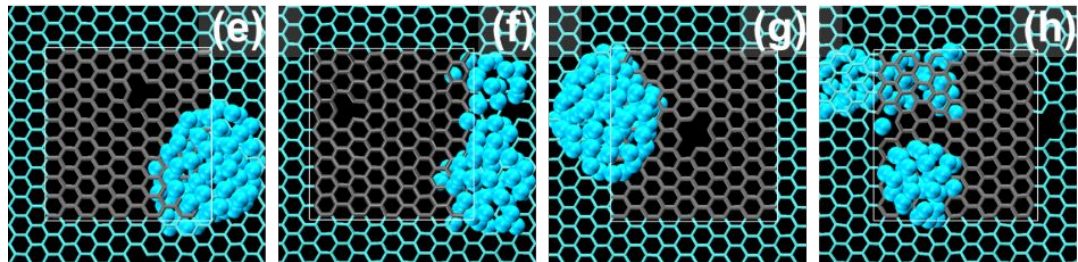

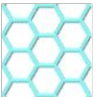

Mapped graphene with PBC
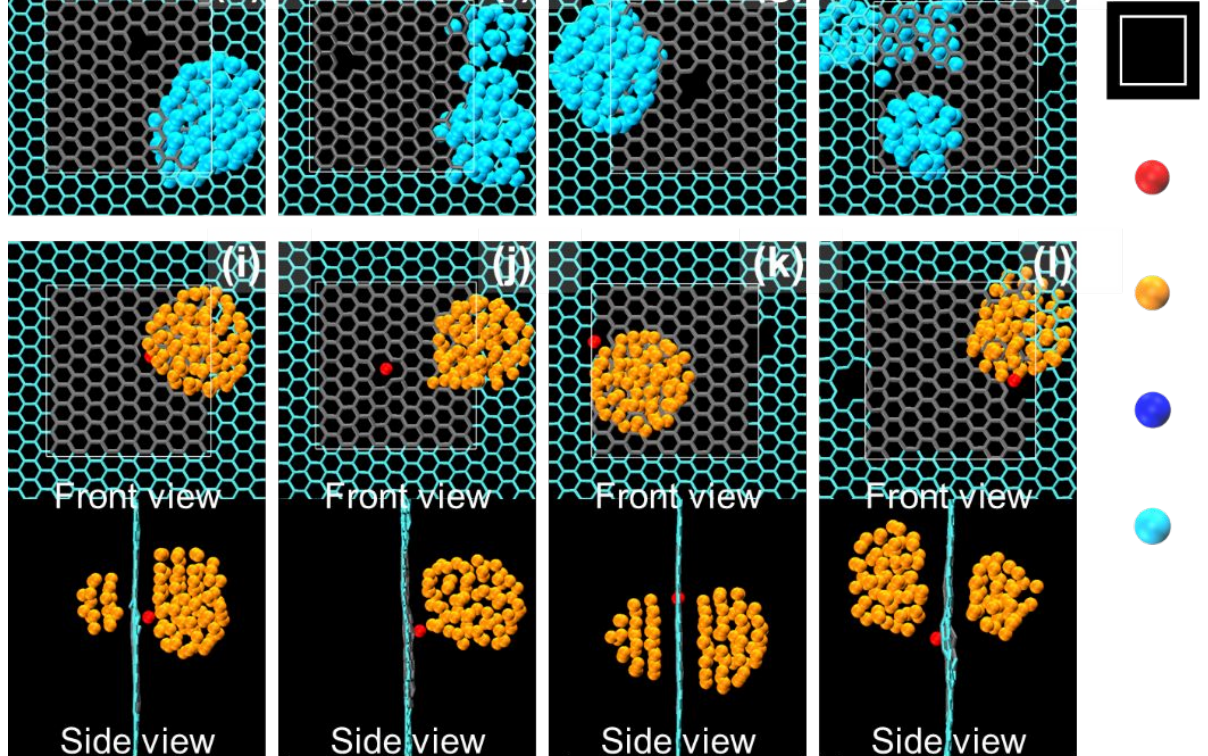

Orthogonal

simulation

box
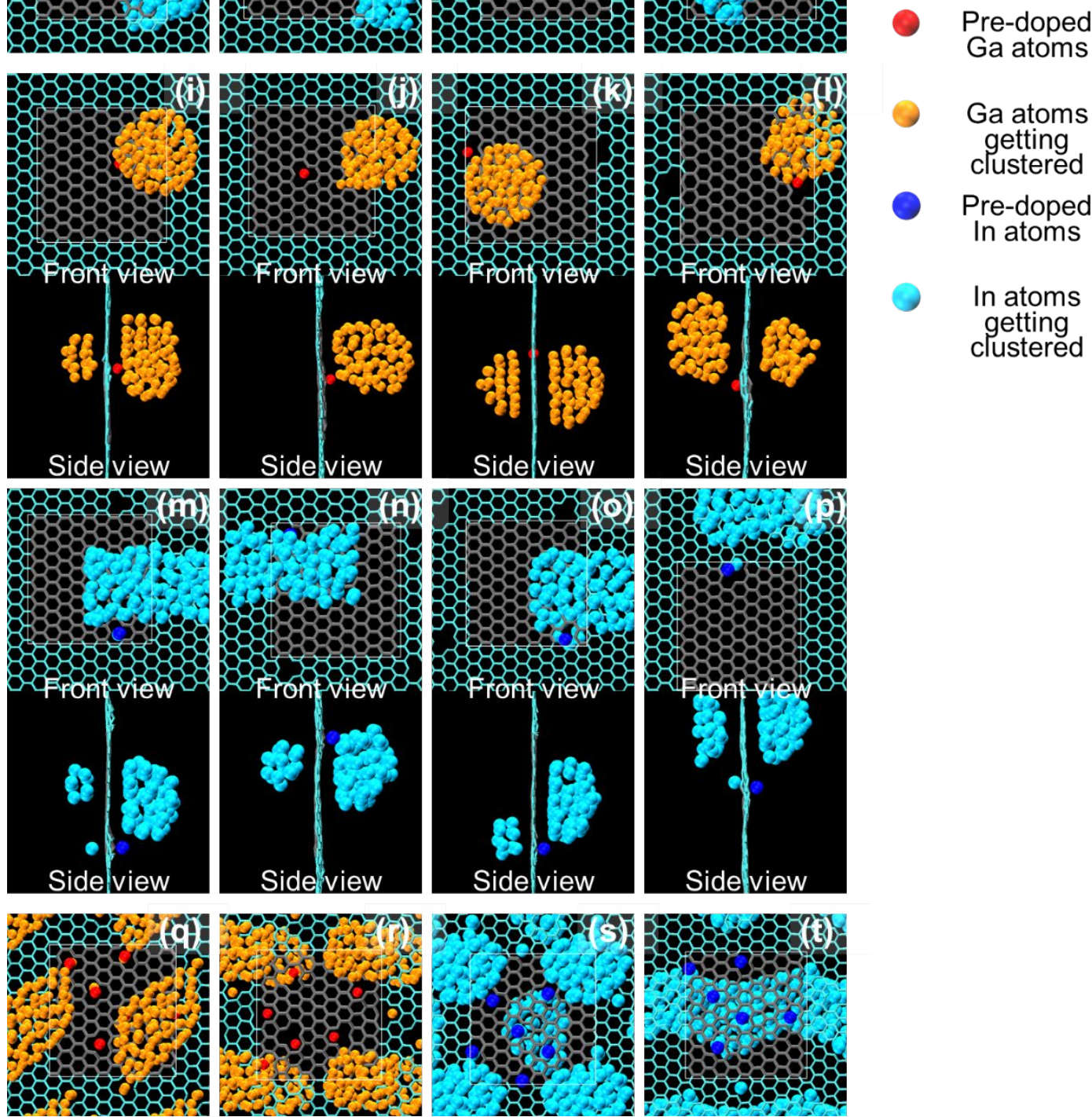

Figure S17. The Ga cluster formation on a bare mono-vacancy graphene (MV-Gr) at (a) $300 \mathrm{~K}$ and (b) $1000 \mathrm{~K}$; the Ga cluster formation on a bare di-vacancy graphene (DV-Gr) at (c) $300 \mathrm{~K}$ and (d) $1000 \mathrm{~K}$. The In cluster formation on a MV-Gr at (e) $300 \mathrm{~K}$ and (f) $1000 \mathrm{~K}$; the In cluster formation on a bare DV-Gr at (g) $300 \mathrm{~K}$ and $(\mathrm{h}) 1000 \mathrm{~K}$. The Ga cluster formation on a pre-doped MVGr at (i) $300 \mathrm{~K}$ and (j) $1000 \mathrm{~K}$ with $v_{2}=5 \mathrm{~mm} / \mathrm{s}$; the Ga cluster formation on a pre-doped DV-Gr at (k) $300 \mathrm{~K}$ and (l) $1000 \mathrm{~K}$ with $v_{2}=5 \mathrm{~mm} / \mathrm{s}$. The In cluster formation on a pre-doped MV-Gr at (m) $300 \mathrm{~K}$ and (n) $1000 \mathrm{~K}$ with $v_{2}=5 \mathrm{~mm} / \mathrm{s}$; the In cluster formation on a pre-doped DV-Gr at (o) $300 \mathrm{~K}$ and (p) $1000 \mathrm{~K}$ with $v_{2}=5 \mathrm{~mm} / \mathrm{s}$. The Ga cluster formation on a graphene with six pre-doped MVs at (q) $300 \mathrm{~K}$ and (r) $1000 \mathrm{~K}$ with $v_{2}=5 \mathrm{~mm} / \mathrm{s}$; the In cluster formation on a graphene with six pre-doped MVs at (s) $300 \mathrm{~K}$ and (t) $1000 \mathrm{~K}$ with $\mathrm{v} 2=5 \mathrm{~mm} / \mathrm{s}$. 

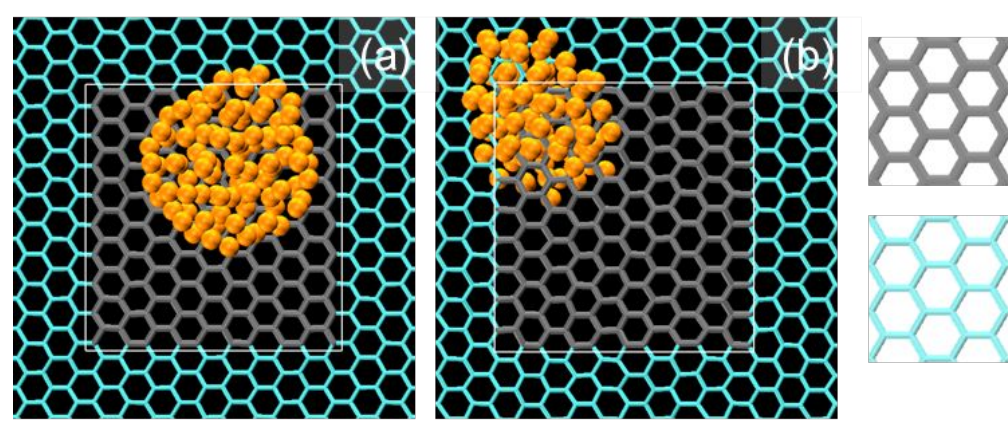

Original

graphene

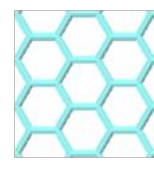

Mapped

graphene

with PBC
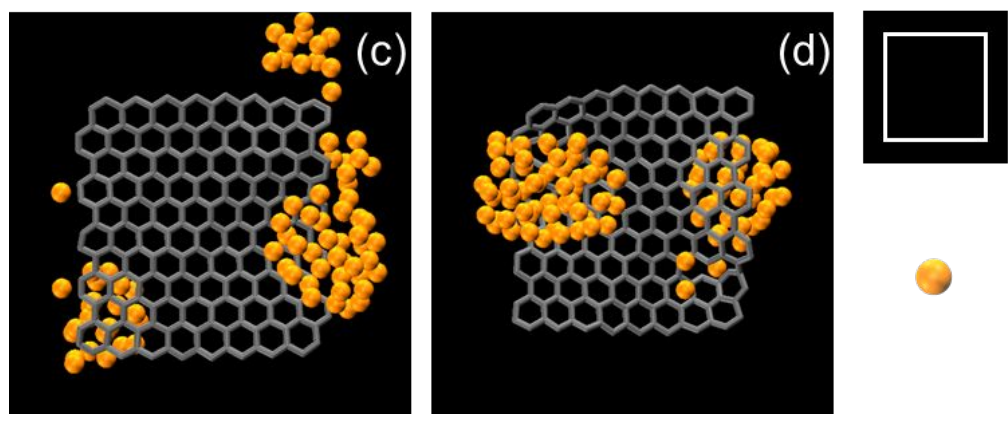

Orthogonal

simulation

box

Ga atoms

getting

clustered

Figure S18. The Ga cluster formation on a pristine graphene with $\mathrm{PBC}$ at (a) $300 \mathrm{~K}$ and (b) $1000 \mathrm{~K}$ with $v_{2}=5 \mathrm{~mm} / \mathrm{s}$; and the Ga cluster formation on a pristine graphene without PBC at (c) $300 \mathrm{~K}$ and (d) $1000 \mathrm{~K}$ with $v_{2}=5 \mathrm{~mm} / \mathrm{s}$. 
Table S1. The ReaxFF calculations of binding energies of a $\mathrm{Ga} / \mathrm{In}$ atom with a $\mathrm{Ga} / \mathrm{In}$ atom in a vacuum, with a $\mathrm{Ga} / \mathrm{In}$ atom absorbed on a pristine graphene, with a Ga/In atom absorbed on a pre-doped MV-Gr, and a Ga/In atom absorbed on a pre-doped DV-Gr.

\begin{tabular}{lc|lc}
\hline \multicolumn{1}{c|}{ Binding Energy of Ga (kcal/mol) } & \multicolumn{1}{c}{ Binding Energy of In (kcal/mol) } \\
\hline Ga in a vacuum & -28.83 & In in a vacuum & -28.24 \\
Gr + Ga & -37.68 & Gr + In & -30.12 \\
MV-Gr + PD Ga & -85.65 & MV-Gr + PD In & -30.21 \\
DV-Gr + PD Ga & -29.70 & DV-Gr + PD In & -30.51 \\
\hline
\end{tabular}
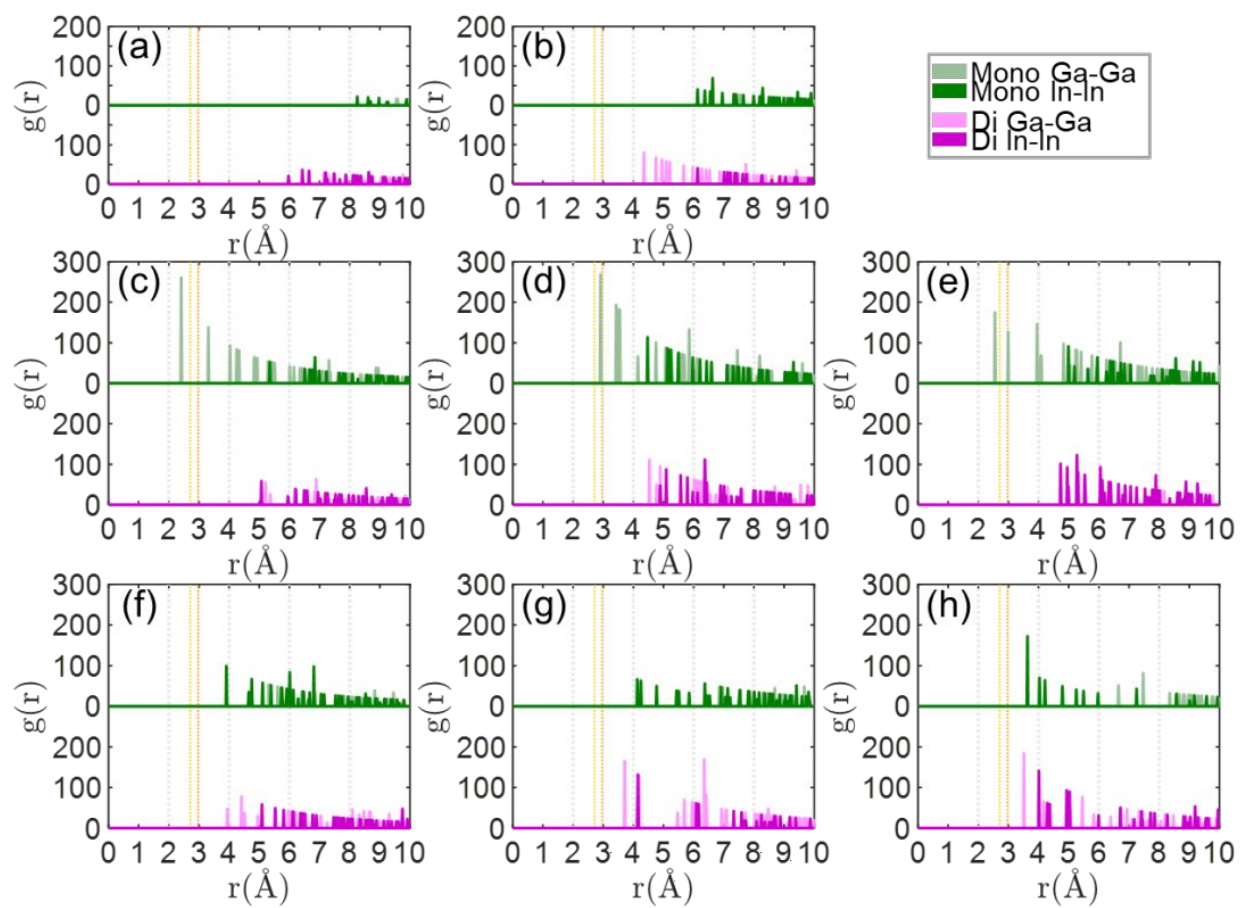

Figure S19. RDF plots of Ga/In clustering on MV-Gr and DV-Gr at (a) 300K without pre-doping or atom gun; and (b) $1000 \mathrm{~K}$ without pre-doping or atom gun. RDF plots of Ga/In clustering on MV-Gr and DV-Gr at (c) T=300K and $v_{1}=0.5 \mathrm{~mm} / \mathrm{s} ;$ (d) $\mathrm{T}=300 \mathrm{~K}$ and $v_{2}=5 \mathrm{~mm} / \mathrm{s} ;$ (e) $\mathrm{T}=300 \mathrm{~K}$ and $v_{3}=50 \mathrm{~mm} / \mathrm{s}$; (f) $\mathrm{T}=1000 \mathrm{~K}$ and $v_{1}=0.5 \mathrm{~mm} / \mathrm{s} ;$ (d) $\mathrm{T}=1000 \mathrm{~K}$ and $v_{2}=5 \mathrm{~mm} / \mathrm{s} ;(\mathrm{e}) \mathrm{T}=1000 \mathrm{~K}$ and $v_{3}=50 \mathrm{~mm} / \mathrm{s}$. 

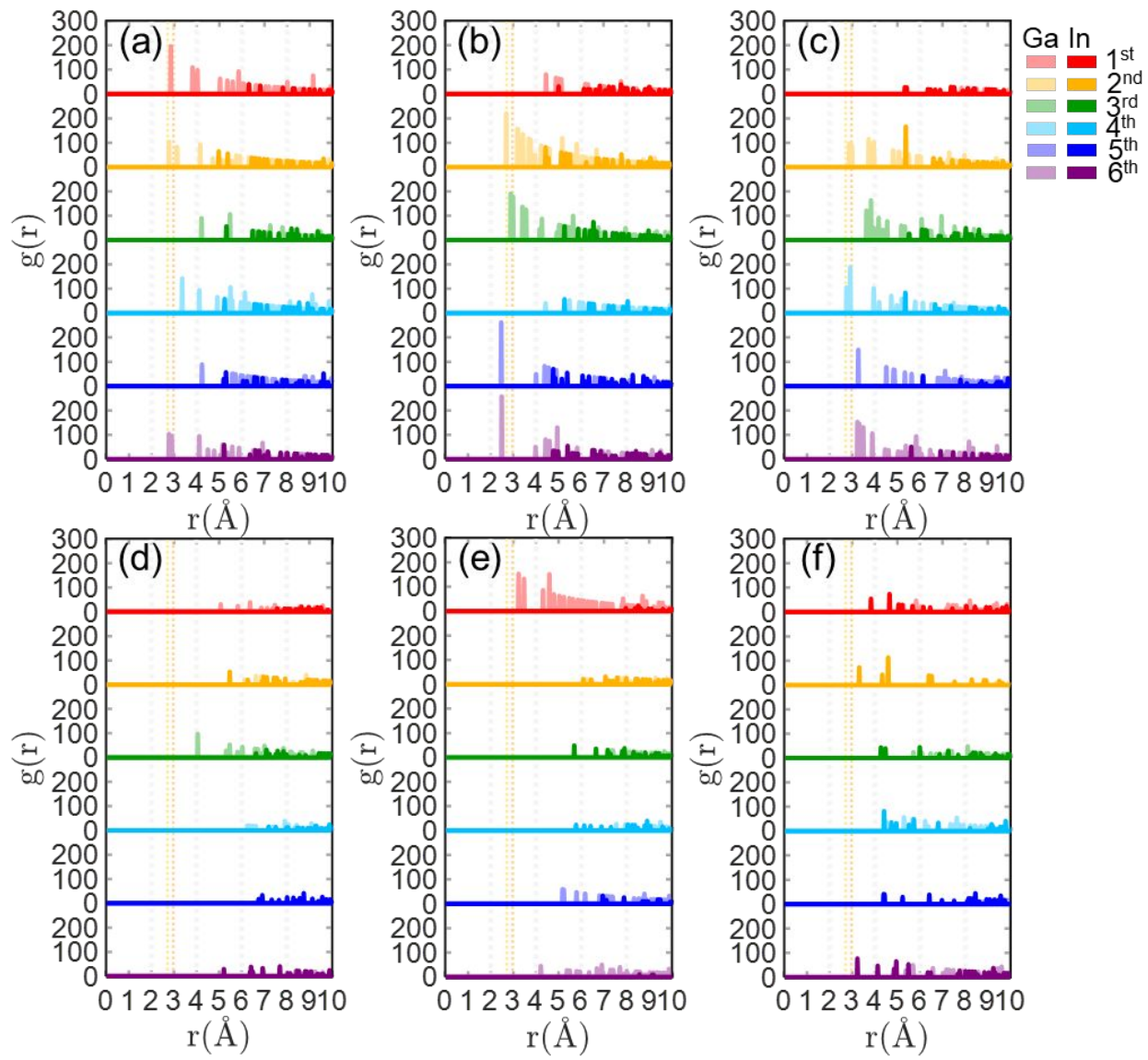

Figure S20. RDF plots of $\mathrm{Ga} / \mathrm{In}$ clustering around 1st to 6th pre-doped MVs of single layer graphene at (a) $\mathrm{T}=300 \mathrm{~K}$ and $v_{1}=0.5 \mathrm{~mm} / \mathrm{s}$; (b) $\mathrm{T}=300 \mathrm{~K}$ and $v_{2}=5 \mathrm{~mm} / \mathrm{s}$; (c) $\mathrm{T}=300 \mathrm{~K}$ and $v_{3}=50 \mathrm{~mm} / \mathrm{s}$; (d) $\mathrm{T}=1000 \mathrm{~K}$ and $v_{1}=0.5 \mathrm{~mm} / \mathrm{s}$; (e) $\mathrm{T}=1000 \mathrm{~K}$ and $v_{2}=5 \mathrm{~mm} / \mathrm{s} ;$ (f) $\mathrm{T}=1000 \mathrm{~K}$ and $v_{3}=50 \mathrm{~mm} / \mathrm{s}$. 

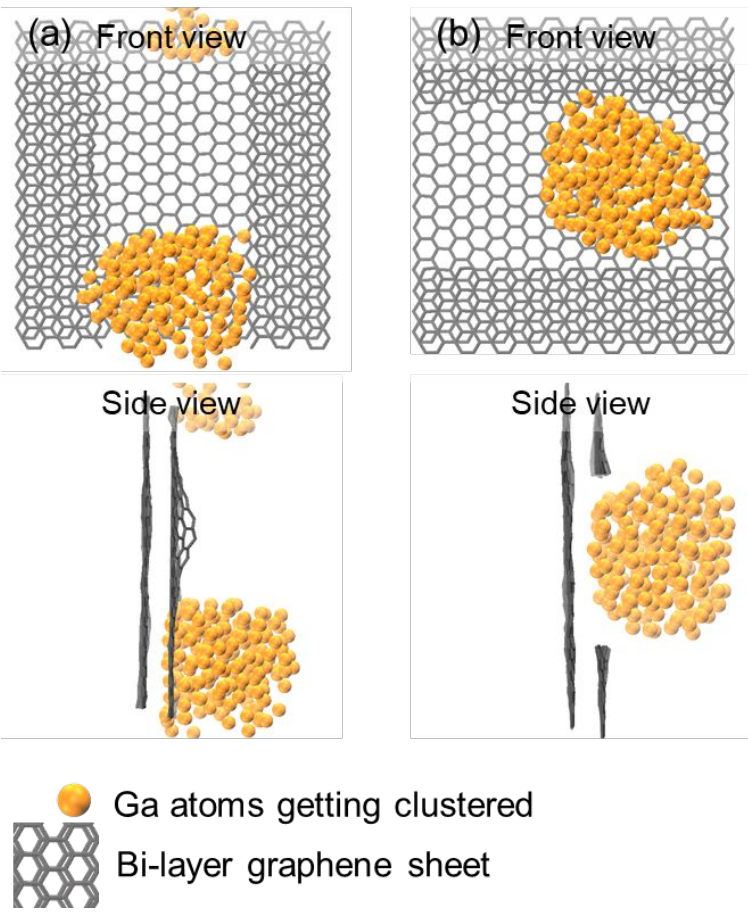

Figure S21. The nucleation and growth of Ga in a spherical shape on the (a) bare ZZ-Gr, and (b) bare AC-Gr. The snapshots are obtained in ReaxFF MD simulations at $\mathrm{T}=1000 \mathrm{~K}$ and $v_{2}=5 \mathrm{~mm} / \mathrm{s}$. 

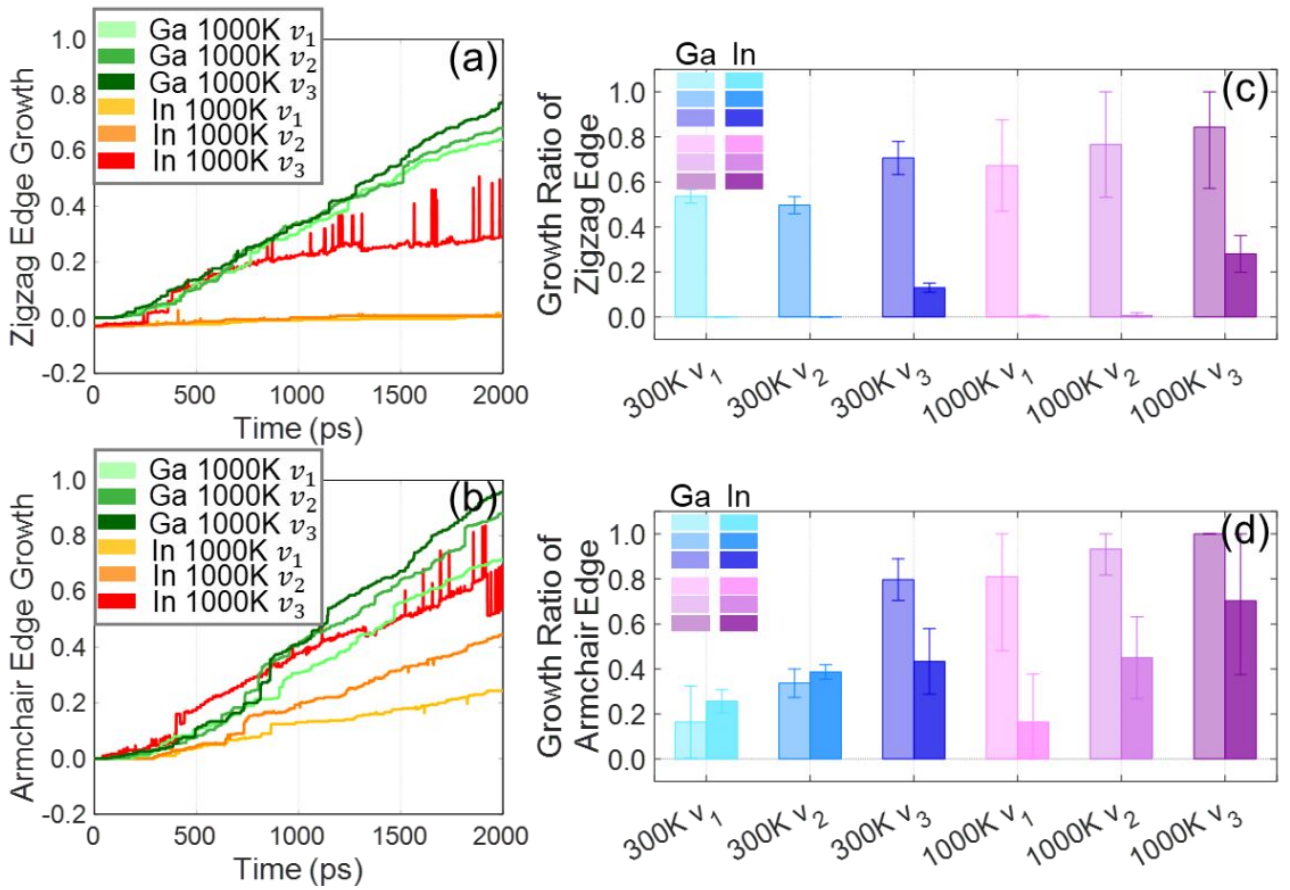

Figure S22. The ratios of Ga/In cluster growth on ZZ-Gr and AC-Gr. The ratios of Ga/In cluster growth on (a) the $\mathrm{ZZ}-\mathrm{Gr}$ and (b) the AC-Gr at different temperatures and shooting velocities during the shooting process. The ratios of $\mathrm{Ga} / \mathrm{In}$ cluster growth on (c) the ZZ-Gr and (d) the AC-Gr at different temperatures and shooting velocities at the end of the equilibration process. 

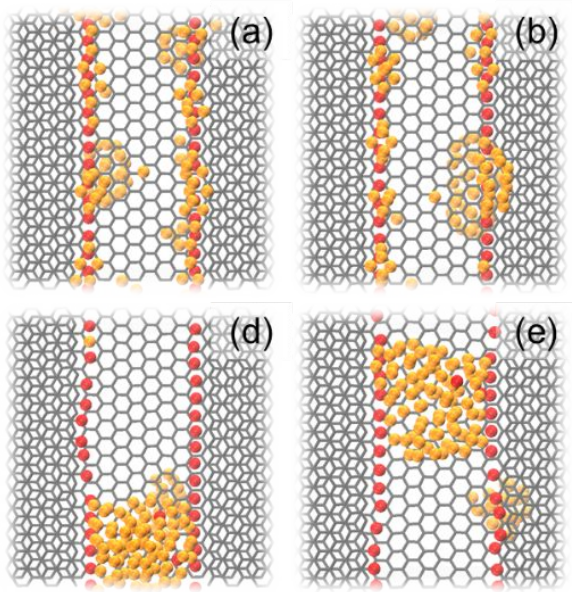

(g)
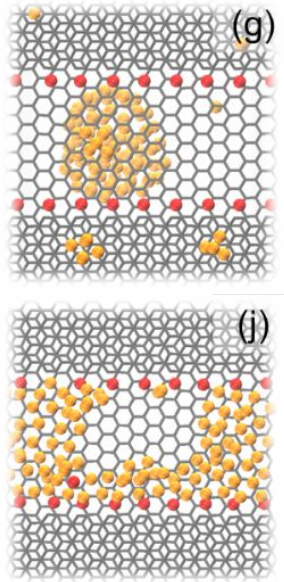

- Pre-doped $\mathrm{Ga}$ atoms

$\mathrm{Ga}$ atoms getting clustered

(h)

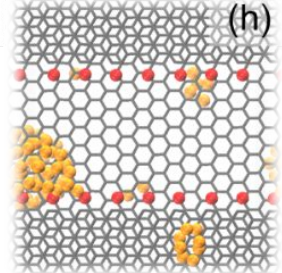

(j)

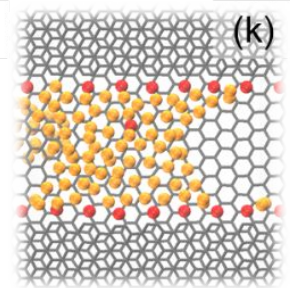

(k)
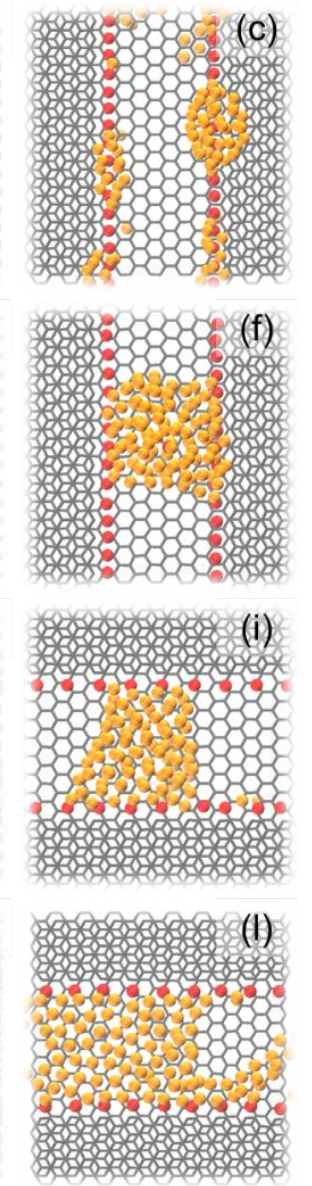

- Pre-doped In atoms

In atoms getting clustered

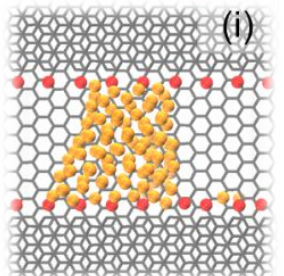

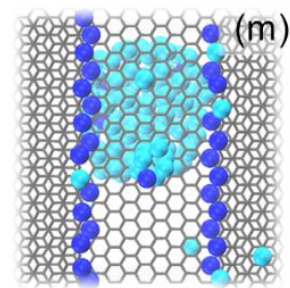
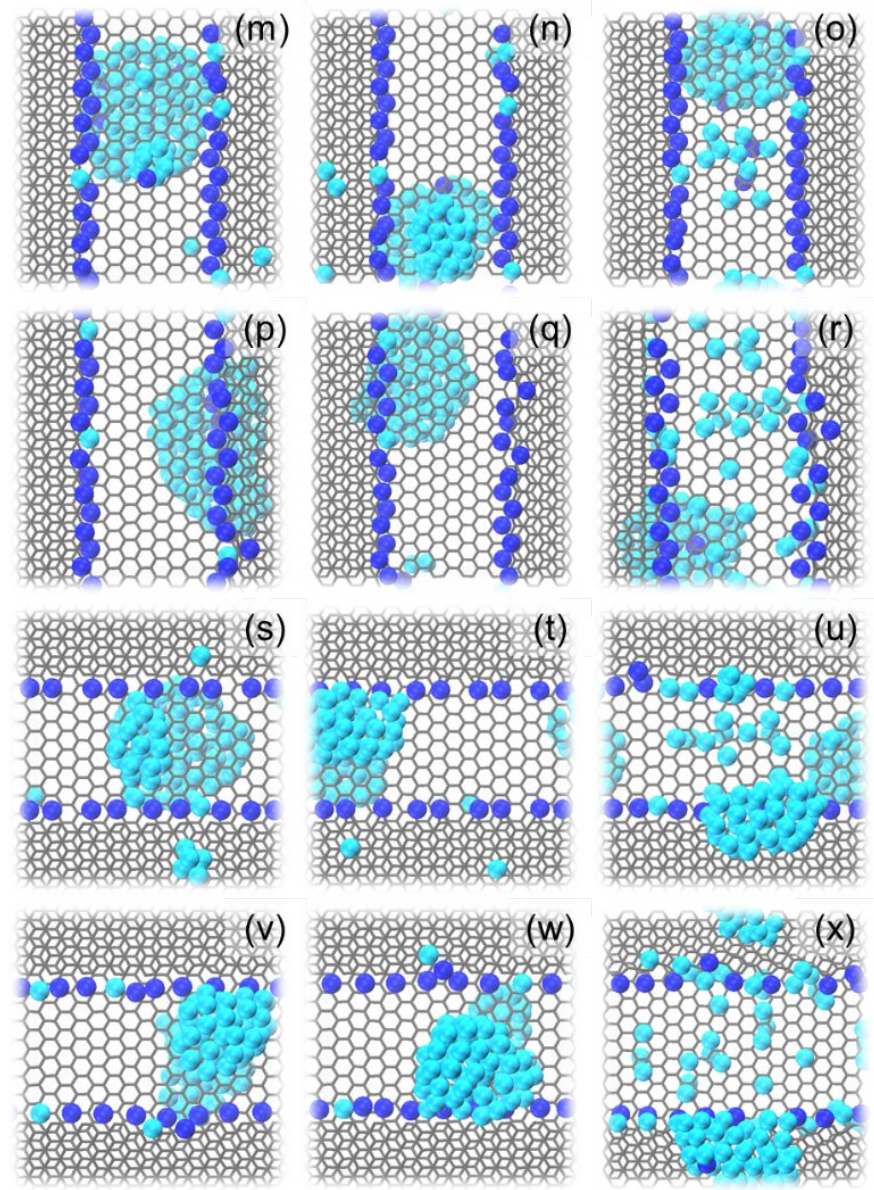

88

Figure S23. The MD snapshots of the Ga/In cluster growth on ZZ-Gr and AC-Gr at the end of the equilibration after the clustering process. Ga cluster growth on (a) the pre-doped ZZ-Gr at T=300K and $v_{1}=0.5 \mathrm{~mm} / \mathrm{s}$; (b) the pre-doped ZZ-Gr at $\mathrm{T}=300 \mathrm{~K}$ and $v_{2}=5 \mathrm{~mm} / \mathrm{s} ;$ (c) the pre-doped ZZ-Gr at T=300K and $v_{3}=50 \mathrm{~mm} / \mathrm{s} ;(\mathrm{d})$ the pre-doped ZZ-Gr at T=1000K and $v_{1}=0.5 \mathrm{~mm} / \mathrm{s} ;$ (e) the pre-doped ZZ-Gr at T=1000K and $v_{2}=5 \mathrm{~mm} / \mathrm{s}$; (f) the pre-doped ZZ-Gr at T=1000K and $v_{3}=50 \mathrm{~mm} / \mathrm{s}$; (g) the pre-doped AC-Gr at T $=300 \mathrm{~K}$ and $v_{1}=0.5 \mathrm{~mm} / \mathrm{s}$; (h) the pre-doped AC-Gr at T=300K and $v_{2}=5 \mathrm{~mm} / \mathrm{s}$; (i) the pre-doped AC-Gr at T $=300 \mathrm{~K}$ and $v_{3}=50 \mathrm{~mm} / \mathrm{s} ;(\mathrm{j})$ the pre-doped AC-Gr at T $=1000 \mathrm{~K}$ and $v_{1}=0.5 \mathrm{~mm} / \mathrm{s} ;(\mathrm{k})$ the pre-doped AC-Gr at $\mathrm{T}=1000 \mathrm{~K}$ and $v_{2}=5 \mathrm{~mm} / \mathrm{s}$; (l) the pre-doped AC-Gr at T=1000K and $v_{3}=50 \mathrm{~mm} / \mathrm{s}$. In cluster growth on $(\mathrm{m})$ the pre-doped ZZ-Gr at T=300K and $v_{1}=0.5 \mathrm{~mm} / \mathrm{s} ;$ (n) the pre-doped ZZ-Gr at T=300K and $v_{2}=5 \mathrm{~mm} / \mathrm{s}$; (o) the pre-doped ZZ-Gr at T=300K and $v_{3}=50 \mathrm{~mm} / \mathrm{s} ;(\mathrm{p})$ the pre-doped ZZ-Gr at T $=1000 \mathrm{~K}$ and $v_{1}=0.5 \mathrm{~mm} / \mathrm{s} ;(\mathrm{q})$ the pre-doped ZZ-Gr at $\mathrm{T}=1000 \mathrm{~K}$ and $v_{2}=5 \mathrm{~mm} / \mathrm{s} ;(\mathrm{r})$ the pre-doped ZZ-Gr at T=1000K and $v_{3}=50 \mathrm{~mm} / \mathrm{s} ;(\mathrm{s})$ the pre-doped AC-Gr at T=300K and $v_{1}=0.5 \mathrm{~mm} / \mathrm{s} ;(\mathrm{t})$ the pre-doped AC-Gr at T $=300 \mathrm{~K}$ and $v_{2}=5 \mathrm{~mm} / \mathrm{s} ;(\mathrm{u})$ the pre-doped AC-Gr at T=300K and $v_{3}=50 \mathrm{~mm} / \mathrm{s} ;(\mathrm{v})$ the pre-doped $\mathrm{AC}-\mathrm{Gr}$ at $\mathrm{T}=1000 \mathrm{~K}$ and $v_{1}=0.5 \mathrm{~mm} / \mathrm{s} ;(\mathrm{w})$ the pre-doped $\mathrm{AC}-\mathrm{Gr}$ at $\mathrm{T}=1000 \mathrm{~K}$ and $v_{2}=5 \mathrm{~mm} / \mathrm{s} ;(\mathrm{x})$ the pre-doped AC-Gr at $\mathrm{T}=1000 \mathrm{~K}$ and $v_{3}=50 \mathrm{~mm} / \mathrm{s}$. 


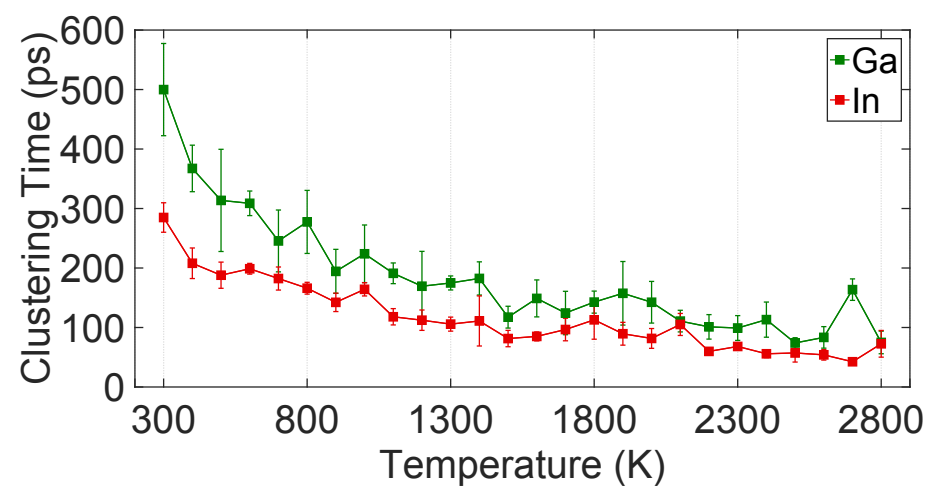

Figure S24. The relationship between clustering time and clustering temperature for the $\mathrm{Ga} / \mathrm{In}$ cluster growth from elemental metallic source. The solid squares represent the mean values averaged from 5 samples, and the error bars represent the associated standard deviations from each case.
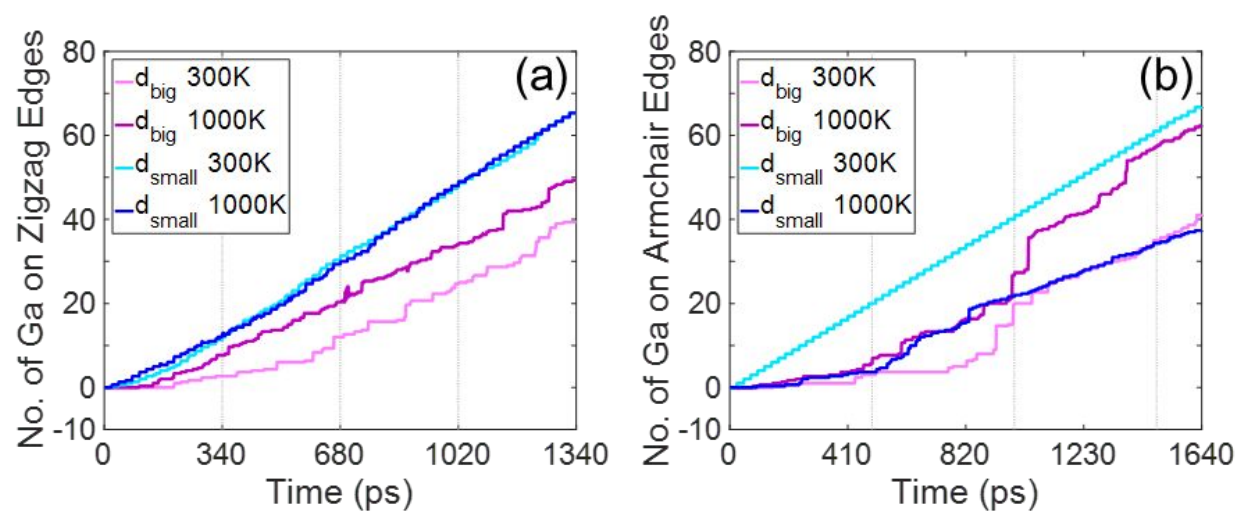

Figure S25. The Ga cluster growth on a pre-doped (a) ZZ-Gr and (b) AC-Gr at $300 \mathrm{~K}$ and $1000 \mathrm{~K}$, with the shooting velocity $\mathrm{v}_{3}=5 \mathrm{~mm} / \mathrm{s}$. The $d_{\text {big }}$ and $d_{\text {mall }}$ in (a) are $18.46 \AA$ and $14.20 \AA$, and $d_{\text {big }}$ and $d_{\text {mall }}$ in (b) are $19.68 \AA$ and $12.30 \AA$. 

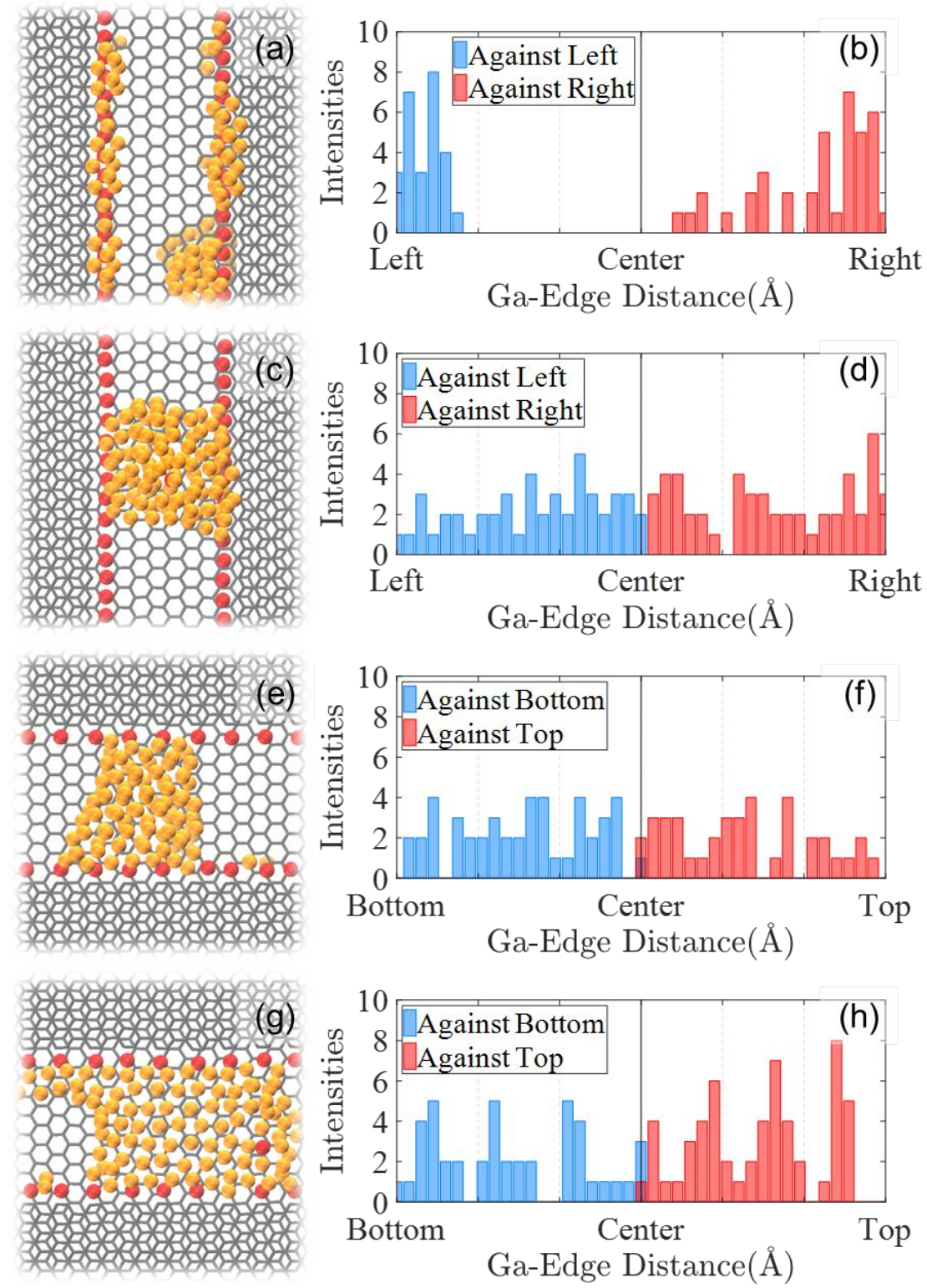

Figure S26. The snapshots of the Ga cluster formation and the Ga-edge distance distributions along the width direction: (a-b) on the ZZ-Gr at T=300K and $v_{3}=50 \mathrm{~mm} / \mathrm{s}$, (c-d) on the ZZ-Gr at T=1000K and $v_{3}=50 \mathrm{~mm} / \mathrm{s}$, (e-f) on the AC-Gr at T=300K and $v_{3}=50 \mathrm{~mm} / \mathrm{s},(\mathrm{g}-\mathrm{h})$ on the AC-Gr at T=1000K and $v_{3}=50 \mathrm{~mm} / \mathrm{s}$. 
Force Fields developed in this study (ReaxFF GaCH-2020 and InCH-2020)

ReaxFF MD-force field: GaCH-2020

39 ! Number of general parameters

$50.0000 ! \mathrm{p}($ boc 1$)$

9.5469 ! $\mathrm{p}($ boc 2$)$

26.5405 ! $\mathrm{p}(\mathrm{coa} 2)$

0.7097 !p(trip4)

2.7376 !p(trip3)

$70.0000 ! \mathrm{kc} 2$

1.0588 ! $\mathrm{p}$ (ovun6)

4.1319 ! (trip2)

12.1176 ! $($ ovun7)

13.3056 ! p(ovun8)

$-68.7063 ! \mathrm{p}($ trip 1$)$

0.0000 !Lower Taper-radius (swa)

10.0000 !Upper Taper-radius (swb)

0.0000 !not used

33.8667 ! $\mathrm{p}(\mathrm{val} 7)$

$6.0891 ! \mathrm{p}(\mathrm{lp} 1)$

1.0563 !p(val9)

$2.0384 ! \mathrm{p}($ val10)

6.1431 !not used

6.9290 !p(pen2)

0.3989 !p(pen 3$)$

3.9954 !p(pen4)

0.0000 !not used

5.7796 !p(tor2)

10.0000 ! $\mathrm{p}$ (tor3)

1.9487 !p(tor4)

0.0000 !not used

2.1645 ! $(\cot 2)$

$1.5591 ! \mathrm{p}(\mathrm{vdW} 1)$

0.1000 !Cutoff for bond order*100 (cutoff)

2.1365 !p(coa4)

0.6991 !p(ovun4)

50.0000 !p(ovun3)

1.8512 !p(val8)

0.0000 !not used

0.0000 !not used

0.0000 !not used 
1.0000 !not used

2.6962 !p(coa3)

3 ! Nr of atoms; atomID;ro(sigma); Val;atom mass;Rvdw;Dij;gamma alfa;gamma(w);Val(angle);p(ovun5);n.u.;chiEEM;etaEEM;n.u. ro(pipi);p(lp2);Heat increment;p(boc4);p(boc3);p(boc5),n.u.;n.u. p(ovun2);p(val3);n.u.;Val(boc);p(val5);n.u.;n.u.;n.u.

C $\quad \begin{array}{llllllll}1.3967 & 4.0000 & 12.0000 & 2.0653 & 0.1084 & 0.9500 & 1.1706 & 4.0000\end{array}$

$\begin{array}{llllllll}9.5656 & 1.5000 & 4.0000 & 27.5134 & 79.5548 & 5.1291 & 7.0520 & 0.0000\end{array}$

$\begin{array}{llllllll}1.1168 & 0.0000 & 181.0000 & 14.2732 & 24.4406 & 6.7313 & 0.8563 & 0.0000\end{array}$

$\begin{array}{lllllllll}-4.1021 & 5.0000 & 1.0564 & 4.0000 & 2.9663 & 0.0000 & 0.0000 & 0.0000\end{array}$

$\begin{array}{llllllllll}\mathrm{H} & 0.9497 & 1.0000 & 1.0080 & 1.1000 & 0.0258 & 0.9900 & -0.1000 & 1.0000\end{array}$

$\begin{array}{lllllllll}9.0873 & 4.5839 & 1.0000 & 0.0000 & 121.1250 & 4.8370 & 9.7728 & 1.0000\end{array}$

$\begin{array}{llllllll}-0.1000 & 0.0000 & 62.4879 & 2.5194 & 2.3785 & 0.2223 & 1.0698 & 0.0000\end{array}$

$\begin{array}{lllllllll}-15.7683 & 2.1488 & 1.0338 & 1.0000 & 2.8793 & 0.0000 & 0.0000 & 0.0000\end{array}$

$\begin{array}{lllllllll}\text { Ga } & 2.0741 & 3.0000 & 69.7230 & 2.2792 & 0.2072 & 0.4750 & -1.6836 & 3.0000\end{array}$

$\begin{array}{lllllllll}9.5119 & 3.9009 & 3.0000 & 0.0076 & 16.5151 & 0.1438 & 6.2943 & 0.0000\end{array}$

$\begin{array}{llllllll}-1.0000 & 0.0000 & 78.4675 & 16.4954 & 0.2500 & 0.0000 & 0.8563 & 0.0000\end{array}$

$\begin{array}{llllllll}-8.0440 & 1.5000 & 1.0338 & 8.0000 & 2.5791 & 0.0000 & 0.0000 & 0.0000\end{array}$

$6 \quad$ ! Nr of bonds; at 1;at2;De(sigma);De(pi);De(pipi);p(be1);p(b p(be2);p(bo3);p(bo4);n.u.;p(bo1);p(bo2)

$\begin{array}{llllllllll}1 & 1 & 82.1865 & 112.8397 & 45.2477 & 0.5521 & -0.5000 & 1.0000 & 34.9859 & 0.7929\end{array}$

$\begin{array}{lllllllll}6.3452 & -0.1772 & 8.1073 & 1.0000 & -0.0695 & 8.0532 & 1.0000 & 0.0000\end{array}$

$\begin{array}{llllllllll}1 & 2 & 179.8121 & 0.0000 & 0.0000 & -0.5072 & 0.0000 & 1.0000 & 6.0000 & 0.6424\end{array}$

$\begin{array}{lllllllll}5.4938 & 1.0000 & 0.0000 & 1.0000 & -0.1172 & 6.5194 & 0.0000 & 0.0000\end{array}$

$\begin{array}{llllllllll}2 & 2 & 114.5085 & 0.0000 & 0.0000 & -0.6444 & 0.0000 & 1.0000 & 6.0000 & 0.8846\end{array}$

$\begin{array}{llllllll}1.7843 & 1.0000 & 0.0000 & 1.0000 & -0.0478 & 5.9268 & 0.0000 & 0.0000\end{array}$

$\begin{array}{llllllllll}3 & 3 & 55.3781 & 0.0000 & 0.0000 & -0.0178 & -0.3000 & 0.0000 & 16.0000 & 0.1752\end{array}$

$\begin{array}{lllllllll}2.8067 & -0.5000 & 25.0000 & 1.0000 & -0.1250 & 5.6472 & 0.0000 & 0.0000\end{array}$

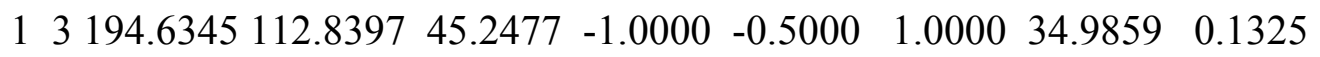

$\begin{array}{llllllll}7.5516 & -0.1772 & 8.1073 & 1.0000 & -0.0813 & 5.9102 & 1.0000 & 0.0000\end{array}$

$\begin{array}{lllllllll}2 & 3300.0000 & 0.0000 & 0.0000 & -1.0000 & 0.0000 & 1.0000 & 6.0000 & 1.0000\end{array}$

$\begin{array}{llllllll}12.1974 & 1.0000 & 0.0000 & 1.0000 & -0.1377 & 6.2939 & 0.0000 & 0.0000\end{array}$

3 ! Nr of off-diagonal terms. at1;at2;Dij;RvdW;alfa;ro(sigma);r

$\begin{array}{llllllll}1 & 2 & 0.1254 & 1.5706 & 9.9698 & 1.2046 & -1.0000 & -1.0000\end{array}$

$\begin{array}{lllllllll}2 & 3 & 0.3000 & 2.1564 & 9.5695 & 1.7552 & -1.0000 & -1.0000\end{array}$

$\begin{array}{llllllll}1 & 3 & 0.3984 & 1.4314 & 13.7875 & 1.7796 & -1.0000 & -1.0000\end{array}$

18 ! Nr of angles. at1;at2;at3;Thetao,o;p(val1);p(val2);p(coa1);

$\begin{array}{llllllllll}1 & 1 & 1 & 75.1328 & 27.4838 & 2.6006 & 0.0000 & 0.0100 & 0.3556 & 1.8543\end{array}$

$\begin{array}{llllllllll}1 & 1 & 2 & 60.6707 & 8.5483 & 3.2240 & 0.0000 & 1.1420 & 0.0114 & 1.5290\end{array}$ 
$\begin{array}{llllllllll}2 & 1 & 2 & 71.7688 & 35.0000 & 3.2124 & 0.0000 & 0.0490 & 0.0000 & 1.0656\end{array}$

$\begin{array}{llllllllll}1 & 2 & 2 & 0.0000 & 3.7388 & 7.6138 & 0.0000 & 0.0000 & 0.0000 & 1.0771\end{array}$

$\begin{array}{llllllllll}1 & 2 & 1 & 0.0000 & 3.4110 & 7.7350 & 0.0000 & 0.0000 & 0.0000 & 1.0400\end{array}$

$\begin{array}{lllllllllll}2 & 2 & 2 & 0.0000 & 27.1364 & 5.7262 & 0.0000 & 0.0000 & 0.0000 & 1.0400\end{array}$

$\begin{array}{lllllllllll}3 & 3 & 3 & 35.1649 & 5.3070 & 1.9255 & 0.0000 & 0.0100 & 0.0000 & 1.1620\end{array}$

$\begin{array}{lllllllllll}1 & 1 & 3 & 0.0125 & 13.3962 & 5.6271 & 0.0000 & 1.3979 & 0.3556 & 1.4266\end{array}$

$\begin{array}{llllllllll}1 & 3 & 1 & 73.7410 & 44.9143 & 3.1080 & 0.0000 & 4.0000 & 0.3556 & 3.6995\end{array}$

$\begin{array}{lllllllllll}3 & 1 & 3 & 11.6076 & 37.7846 & 0.8844 & 0.0000 & 1.6337 & 0.3556 & 4.0000\end{array}$

$\begin{array}{llllllllll}1 & 3 & 3 & 75.1328 & 27.4838 & 2.6006 & 0.0000 & 0.0100 & 0.3556 & 1.8543\end{array}$

$\begin{array}{llllllllll}1 & 3 & 2 & 29.6768 & 33.2277 & 2.3803 & 0.0000 & 4.0000 & 0.0114 & 1.0000\end{array}$

$\begin{array}{llllllllll}2 & 1 & 3 & 33.1237 & 2.8139 & 7.9998 & 0.0000 & 0.5624 & 0.0114 & 3.3075\end{array}$

$\begin{array}{llllllllll}2 & 3 & 3 & 60.6707 & 8.5483 & 3.2240 & 0.0000 & 1.1420 & 0.0114 & 1.5290\end{array}$

$\begin{array}{lllllllllll}2 & 3 & 2 & 62.6808 & 50.0000 & 1.4522 & 0.0000 & 0.0100 & 0.0000 & 1.0472\end{array}$

$\begin{array}{lllllllllll}2 & 2 & 3 & 0.0000 & 3.7388 & 7.6138 & 0.0000 & 0.0000 & 0.0000 & 1.0771\end{array}$

$\begin{array}{llllllllll}1 & 2 & 3 & 0.0000 & 3.4110 & 7.7350 & 0.0000 & 0.0000 & 0.0000 & 1.0400\end{array}$

$\begin{array}{llllllllll}3 & 2 & 3 & 0.0000 & 3.4110 & 7.7350 & 0.0000 & 0.0000 & 0.0000 & 1.0400\end{array}$

8 ! Nr of torsions. at 1 ; 2 ; at $3 ; \mathrm{at} 4 ; ; \mathrm{V} 1 ; \mathrm{V} 2 ; \mathrm{V} 3 ; \mathrm{p}($ tor 1$) ; \mathrm{p}(\cot 1) ; \mathrm{n}$

$\begin{array}{llllllllllll}1 & 1 & 1 & 1 & 2.0000 & 18.9182 & 0.0100 & -6.5704 & -2.6029 & 0.0000 & 0.0000\end{array}$

$\begin{array}{llllllllllll}1 & 1 & 1 & 2 & 1.3170 & 79.8617 & -0.2022 & -6.3640 & -2.6774 & 0.0000 & 0.0000\end{array}$

$\begin{array}{llllllllllll}2 & 1 & 1 & 2 & 2.0337 & 79.9898 & 0.4134 & -8.2236 & -7.9500 & 0.0000 & 0.0000\end{array}$

$\begin{array}{llllllllllll}0 & 1 & 2 & 0 & 0.0000 & 0.0000 & 0.0000 & 0.0000 & 0.0000 & 0.0000 & 0.0000\end{array}$

$\begin{array}{lllllllllllll}0 & 2 & 2 & 0 & 0.0000 & 0.0000 & 0.0000 & 0.0000 & 0.0000 & 0.0000 & 0.0000\end{array}$

$\begin{array}{lllllllllllll}0 & 1 & 1 & 0 & 0.0000 & 50.0000 & 0.3000 & -4.0000 & -2.0000 & 0.0000 & 0.0000\end{array}$

$\begin{array}{llllllllllll}1 & 1 & 1 & 3 & 0.0100 & 27.8389 & 0.0100 & -6.1891 & -3.9633 & 0.0000 & 0.0000\end{array}$

$\begin{array}{llllllllllll}1 & 1 & 3 & 1 & 0.1926 & 102.7457 & 0.5015 & -3.0933 & -4.8168 & 0.0000 & 0.0000\end{array}$

$0 \quad$ ! Nr of hydrogen bonds. at $1 ; \mathrm{at} 2 ; \mathrm{at} 3 ; \mathrm{r}(\mathrm{hb}) ; \mathrm{p}(\mathrm{hb} 1) ; \mathrm{p}(\mathrm{hb} 2) ; \mathrm{p}(\mathrm{hb3})$ 


\section{ReaxFF MD-force field: InCH-2020}

39 ! Number of general parameters

50.0000 !p(boc1)

$9.5469 ! \mathrm{p}($ boc 2$)$

26.5405 ! $\mathrm{p}(\mathrm{coa} 2)$

0.7097 !p(trip4)

2.7376 !p(trip3)

70.0000 !kc2

1.0588 !p(ovun6)

$4.1319 ! \mathrm{p}(\operatorname{trip} 2)$

12.1176 ! p(ovun7)

13.3056 ! $\mathrm{p}$ (ovun8)

-68.7063 !p(trip1)

0.0000 !Lower Taper-radius (swa)

10.0000 !Upper Taper-radius (swb)

0.0000 !not used

33.8667 !p(val7)

6.0891 !p(lp1)

1.0563 !p(val9)

2.0384 !p(val10)

6.1431 !not used

6.9290 !p(pen2)

0.3989 !p(pen3)

3.9954 !p(pen4)

0.0000 !not used

5.7796 !p(tor2)

10.0000 !p(tor3)

1.9487 !p(tor4)

0.0000 !not used

2.1645 !p $(\cot 2)$

1.5591 !p(vdW1)

0.1000 !Cutoff for bond order*100 (cutoff)

2.1365 !p(coa4)

$0.6991 ! \mathrm{p}($ ovun4)

$50.0000 ! \mathrm{p}($ ovun3)

1.8512 !p(val8)

0.0000 !not used

0.0000 !not used

0.0000 !not used

1.0000 !not used 
$2.6962 ! \mathrm{p}(\mathrm{coa} 3)$

3 ! Nr of atoms; atomID;ro(sigma); Val;atom mass;Rvdw;Dij;gamma alfa;gamma(w);Val(angle);p(ovun5);n.u.;chiEEM;etaEEM;n.u. ro(pipi);p(lp2);Heat increment;p(boc4);p(boc3);p(boc5),n.u.;n.u. p(ovun2);p(val3);n.u.; $\operatorname{Val(boc);p(val5);n.u.;n.u.;n.u.~}$

$\begin{array}{lllllllll}\text { C } & 1.3967 & 4.0000 & 12.0000 & 2.0653 & 0.1084 & 0.9500 & 1.1706 & 4.0000\end{array}$

$\begin{array}{lllllllll}9.5656 & 1.5000 & 4.0000 & 27.5134 & 79.5548 & 5.1291 & 7.0520 & 0.0000\end{array}$

$\begin{array}{llllllll}1.1168 & 0.0000 & 181.0000 & 14.2732 & 24.4406 & 6.7313 & 0.8563 & 0.0000\end{array}$

$\begin{array}{lllllllll}-4.1021 & 5.0000 & 1.0564 & 4.0000 & 2.9663 & 0.0000 & 0.0000 & 0.0000\end{array}$

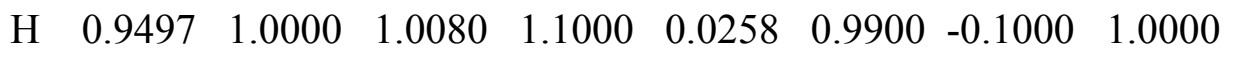

$\begin{array}{lllllllll}9.0873 & 4.5839 & 1.0000 & 0.0000 & 121.1250 & 4.8370 & 9.7728 & 1.0000\end{array}$

$\begin{array}{llllllll}-0.1000 & 0.0000 & 62.4879 & 2.5194 & 2.3785 & 0.2223 & 1.0698 & 0.0000\end{array}$

$\begin{array}{lllllllll}-15.7683 & 2.1488 & 1.0338 & 1.0000 & 2.8793 & 0.0000 & 0.0000 & 0.0000\end{array}$

$\begin{array}{lllllllll}\text { In } \quad 2.2454 & 3.0000 & 114.8180 & 2.4712 & 0.2712 & 1.0000 & -1.6836 & 3.0000\end{array}$

$\begin{array}{lllllllll}9.0000 & 3.9009 & 3.0000 & 0.0076 & 16.5151 & -1.0703 & 6.4828 & 0.0000\end{array}$

$\begin{array}{lllllllll}-1.0000 & 0.0000 & 78.4675 & 29.8972 & 0.5469 & 0.0000 & 0.8563 & 0.0000\end{array}$

$\begin{array}{llllllll}-6.1184 & 1.5000 & 1.0338 & 8.0000 & 2.5791 & 0.0000 & 0.0000 & 0.0000\end{array}$

$6 \quad$ ! Nr of bonds; at1;at2;De(sigma);De(pi);De(pipi);p(be1);p(b p(be2);p(bo3);p(bo4);n.u.;p(bo1);p(bo2)

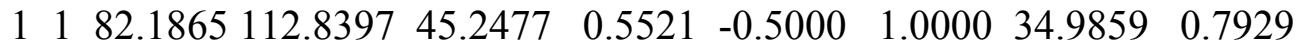

$\begin{array}{llllllll}6.3452 & -0.1772 & 8.1073 & 1.0000 & -0.0695 & 8.0532 & 1.0000 & 0.0000\end{array}$

$\begin{array}{llllllllll}1 & 2 & 179.8121 & 0.0000 & 0.0000 & -0.5072 & 0.0000 & 1.0000 & 6.0000 & 0.6424\end{array}$

$\begin{array}{lllllllll}5.4938 & 1.0000 & 0.0000 & 1.0000 & -0.1172 & 6.5194 & 0.0000 & 0.0000\end{array}$

$\begin{array}{llllllllll}2 & 2 & 114.5085 & 0.0000 & 0.0000 & -0.6444 & 0.0000 & 1.0000 & 6.0000 & 0.8846\end{array}$

$\begin{array}{lllllllll}1.7843 & 1.0000 & 0.0000 & 1.0000 & -0.0478 & 5.9268 & 0.0000 & 0.0000\end{array}$

$\begin{array}{llllllllll}3 & 3 & 52.4915 & 0.0000 & 0.0000 & -0.4257 & -0.3000 & 0.0000 & 16.0000 & 0.2010\end{array}$

$\begin{array}{lllllllll}0.8736 & -0.5000 & 25.0000 & 1.0000 & -0.0838 & 5.7265 & 0.0000 & 0.0000\end{array}$

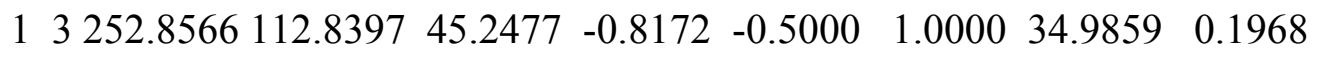

$\begin{array}{lllllllll}7.2259 & -0.1772 & 8.1073 & 1.0000 & -0.1339 & 4.5743 & 1.0000 & 0.0000\end{array}$

$\begin{array}{lllllllll}2 & 3226.6109 & 0.0000 & 0.0000 & -1.0000 & 0.0000 & 1.0000 & 6.0000 & 0.3879\end{array}$

$\begin{array}{lllllllll}10.6241 & 1.0000 & 0.0000 & 1.0000 & -0.0889 & 6.3362 & 0.0000 & 0.0000\end{array}$

3 ! Nr of off-diagonal terms. at1;at2;Dij;RvdW;alfa;ro(sigma);r

$\begin{array}{llllllll}1 & 2 & 0.1254 & 1.5706 & 9.9698 & 1.2046 & -1.0000 & -1.0000\end{array}$

$\begin{array}{lllllllll}2 & 3 & 0.3000 & 2.2000 & 9.7076 & 1.7722 & -1.0000 & -1.0000\end{array}$

$\begin{array}{llllllll}1 & 3 & 0.2857 & 1.6929 & 12.7776 & 1.8412 & -1.0000 & -1.0000\end{array}$

18 ! Nr of angles. at1;at2;at3;Thetao,o;p(val1);p(val2);p(coa1);

$\begin{array}{llllllllll}1 & 1 & 1 & 75.1328 & 27.4838 & 2.6006 & 0.0000 & 0.0100 & 0.3556 & 1.8543\end{array}$

$\begin{array}{llllllllll}1 & 1 & 2 & 60.6707 & 8.5483 & 3.2240 & 0.0000 & 1.1420 & 0.0114 & 1.5290\end{array}$

$\begin{array}{lllllllllll}2 & 1 & 2 & 71.7688 & 35.0000 & 3.2124 & 0.0000 & 0.0490 & 0.0000 & 1.0656\end{array}$

$\begin{array}{llllllllll}1 & 2 & 2 & 0.0000 & 3.7388 & 7.6138 & 0.0000 & 0.0000 & 0.0000 & 1.0771\end{array}$ 
$\begin{array}{llllllllll}1 & 2 & 1 & 0.0000 & 3.4110 & 7.7350 & 0.0000 & 0.0000 & 0.0000 & 1.0400\end{array}$

$\begin{array}{lllllllllll}2 & 2 & 2 & 0.0000 & 27.1364 & 5.7262 & 0.0000 & 0.0000 & 0.0000 & 1.0400\end{array}$

$\begin{array}{lllllllllll}3 & 3 & 3 & 46.4271 & 5.2373 & 1.3412 & 0.0000 & 1.0000 & 0.0000 & 1.4386\end{array}$

$\begin{array}{lllllllllll}1 & 1 & 3 & 50.3761 & 14.3541 & 8.0000 & 0.0000 & 4.0000 & 0.3556 & 1.1704\end{array}$

$\begin{array}{llllllllll}13 & 1 & 90.0000 & 43.2339 & 0.3487 & 0.0000 & 0.7371 & 0.3556 & 1.0000\end{array}$

$\begin{array}{lllllllllll}3 & 1 & 3 & 10.5896 & 24.8360 & 0.9858 & 0.0000 & 2.7179 & 0.3556 & 1.0920\end{array}$

$\begin{array}{llllllllll}1 & 3 & 3 & 75.1328 & 27.4838 & 2.6006 & 0.0000 & 0.0100 & 0.3556 & 1.8543\end{array}$

$\begin{array}{llllllllll}1 & 3 & 2 & 49.0748 & 29.1903 & 1.2103 & 0.0000 & 3.5092 & 0.0114 & 1.0000\end{array}$

$\begin{array}{llllllllll}2 & 1 & 3 & 23.7420 & 7.9779 & 4.6658 & 0.0000 & 1.7085 & 0.0114 & 2.0937\end{array}$

$\begin{array}{lllllllllll}2 & 3 & 3 & 60.6707 & 8.5483 & 3.2240 & 0.0000 & 1.1420 & 0.0114 & 1.5290\end{array}$

$\begin{array}{lllllllllll}2 & 3 & 2 & 64.7681 & 7.6428 & 3.7784 & 0.0000 & 2.0525 & 0.0000 & 2.4006\end{array}$

$\begin{array}{llllllllll}2 & 2 & 3 & 0.0000 & 3.7388 & 7.6138 & 0.0000 & 0.0000 & 0.0000 & 1.0771\end{array}$

$\begin{array}{llllllllll}1 & 2 & 3 & 0.0000 & 3.4110 & 7.7350 & 0.0000 & 0.0000 & 0.0000 & 1.0400\end{array}$

$\begin{array}{llllllllll}3 & 2 & 3 & 0.0000 & 3.4110 & 7.7350 & 0.0000 & 0.0000 & 0.0000 & 1.0400\end{array}$

7 ! Nr of torsions. at1;at2;at3;at4;;V1;V2;V3;p(tor1);p(cot1);n

$\begin{array}{lllllllllllll}1 & 1 & 1 & 1 & 2.0000 & 18.9182 & 0.0100 & -6.5704 & -2.6029 & 0.0000 & 0.0000\end{array}$

$\begin{array}{llllllllllll}1 & 1 & 1 & 2 & 1.3170 & 79.8617 & -0.2022 & -6.3640 & -2.6774 & 0.0000 & 0.0000\end{array}$

$\begin{array}{llllllllllll}2 & 1 & 1 & 2 & 2.0337 & 79.9898 & 0.4134 & -8.2236 & -7.9500 & 0.0000 & 0.0000\end{array}$

$\begin{array}{llllllllllll}0 & 1 & 2 & 0 & 0.0000 & 0.0000 & 0.0000 & 0.0000 & 0.0000 & 0.0000 & 0.0000\end{array}$

$\begin{array}{llllllllllll}0 & 2 & 2 & 0 & 0.0000 & 0.0000 & 0.0000 & 0.0000 & 0.0000 & 0.0000 & 0.0000\end{array}$

$\begin{array}{lllllllllllll}0 & 1 & 1 & 0 & 0.0000 & 50.0000 & 0.3000 & -4.0000 & -2.0000 & 0.0000 & 0.0000\end{array}$

$\begin{array}{llllllllllll}1 & 1 & 1 & 3 & 0.0100 & 79.8108 & 0.0100 & -8.3710 & -3.9633 & 0.0000 & 0.0000\end{array}$

$0 \quad$ ! Nr of hydrogen bonds. at1;at2;at3;r(hb);p(hb1);p(hb2);p(hb3) 